NBER WORKING PAPER SERIES

\title{
HOW COSTLY IS DIVERSITY? AFFIRMATIVE ACTION IN LIGHT OF GENDER DIFFERENCES IN COMPETITIVENESS
}

\author{
Muriel Niederle \\ Carmit Segal \\ Lise Vesterlund \\ Working Paper 13923 \\ http://www.nber.org/papers/w13923
NATIONAL BUREAU OF ECONOMIC RESEARCH
1050 Massachusetts Avenue
Cambridge, MA 02138
April 2008

We are grateful to the NSF and the Harvard Business School for generous support. We thank the following institutions for their hospitality: Institute for Advanced Study at Princeton and the Department of Economics at Harvard (Niederle), Harvard Business School (Segal) and CEBR at Copenhagen Business School (Vesterlund). The views expressed herein are those of the author(s) and do not necessarily reflect the views of the National Bureau of Economic Research.

NBER working papers are circulated for discussion and comment purposes. They have not been peerreviewed or been subject to the review by the NBER Board of Directors that accompanies official NBER publications.

(C) 2008 by Muriel Niederle, Carmit Segal, and Lise Vesterlund. All rights reserved. Short sections of text, not to exceed two paragraphs, may be quoted without explicit permission provided that full credit, including $\odot$ notice, is given to the source. 
How Costly is Diversity? Affirmative Action in Light of Gender Differences in Competitiveness Muriel Niederle, Carmit Segal, and Lise Vesterlund

NBER Working Paper No. 13923

April 2008

JEL No. C91,J16,J24

\begin{abstract}
Recent research documents that while men are eager to compete, women often shy away from competitive environments. A consequence is that few women enter and win competitions. Using experimental methods we examine how affirmative action affects competitive entry. We find that when women are guaranteed equal representation among winners, more women and fewer men enter competitions, and the response exceeds that predicted by changes in the probability of winning. An explanation for this response is that under affirmative action the probability of winning depends not only on one's rank relative to other group members, but also on one's rank within gender. Both beliefs on rank and attitudes towards competition change when moving to a more gender-specific competition. The changes in competitive entry have important implications when assessing the costs of affirmative action. Based on ex-ante tournament entry affirmative action is predicted to lower the performance requirement for women and thus result in reverse discrimination towards men. Interestingly this need not be the outcome when competitive entry is not payoff maximizing. The response in entry implies that it may not be necessary to lower the performance requirement for women to achieve a more diverse set of winners.
\end{abstract}

\author{
Muriel Niederle \\ Department of Economics \\ 579 Serra Mall \\ Stanford University \\ Stanford, CA 94305-6072 \\ and NBER \\ niederle@stanford.edu \\ Carmit Segal \\ Department of Economics and Business \\ Universitat Pompeu Fabra \\ Jaume I building \\ Ramon Trias Fargas, 25-27 \\ Barcelona, 08005 \\ Spain \\ carmit.segal@upf.edu
}

\author{
Lise Vesterlund \\ Department of Economics \\ University of Pittsburgh \\ 4916 W.W. Posvar Hall \\ Pittsburgh, PA 15260 \\ vester@pitt.edu
}




\section{INTRODUCTION}

Despite decades of striving for gender equality, large differences still remain between men and women in the labor market. Perhaps most noteworthy is the gender segregation across different types of jobs. While there is substantial horizontal segregation, with women more likely to hold clerical or nurturing jobs and men more visible in manufacturing, the vertical segregation within a sector is particularly striking (Weeden, 2004, and Grusky and England, 2004, Ander, 1998). Across fields men are disproportionately allocated to professional and managerial occupations. In a large sample of US firms Bertrand and Hallock (2001) show that women only account for 2.5 percent of the five highest paid executives. ${ }^{1}$ While it may be argued that such segregation is a result of past history, and that these differences will diminish over time, it is noteworthy that women are underrepresented among the people who have the minimum training frequently required for senior management. Only 30 percent of students at top tier business schools are women, and, relative to their male counterparts, female MBA's are more likely to work in the non-profit sector, work part time, or entirely drop out of the work force. ${ }^{2}$

It is commonly argued that discrimination, preference differences for child rearing, and ability differences can explain the absence of women in upper level management. ${ }^{3}$ Recent research suggests that an additional explanation is that women are more reluctant to put themselves in a position where they have to compete against others (see e.g., Gneezy and Rustichini, 2005, Gupta, Poulsen and Villeval, 2005, and Niederle and Vesterlund, 2007, henceforth NV). ${ }^{4}$ For example, NV examines compensation choices in an environment where men and women are equally good at competing. They find that the majority of men select the competitive tournament whereas the majority of women select the non-competitive piece rate. While low ability men are found to compete too much, high ability women compete too little, and few women succeed in and win the tournament.

From the firm's perspective it is particularly costly if the upper tail of the performance distribution does not enter competitions for jobs or promotions. As explained by B. Joseph White, president of University of Illinois, "Getting more women into MBA programs means

\footnotetext{
${ }^{1}$ Similarly only about 17 percent of the partners at major law firms nationwide were women in 2005 (Timothy O'Brien, The New York Times, March 19, 2006).

${ }^{2}$ E.g., Hewlett and Luce, 2005. See also Blau and Kahn, 2004.

${ }^{3}$ See Altonji and Blank (1999), Black and Strahan (2001), and Goldin and Rouse (2000).

${ }^{4}$ The Babcock and Laschever (2003) finding that women are more reluctant to negotiate may also be seen as evidence of gender differences in willingness to compete.
} 
better access to the total talent pool for business". 5 An additional argument for increasing the number of women in top managerial positions is that diversity in and of itself may benefit the firm. ${ }^{6}$ Indeed US corporations are concerned by their inability to attain and recruit women, and they are increasingly developing programs to improve the number of women employees. ${ }^{7}$

When instituting programs to alter the gender composition in certain jobs it is of course important that we understand how these programs influence behavior. To begin this process, we use experiments to investigate how affirmative action may affect participants' willingness to compete. Specifically, we consider a quota system which requires that out of two winners of a tournament at least one must be a woman. ${ }^{8}$ We examine the consequences such a system may have on the individual's decision to compete and thereby on the resulting gender composition of the applicant pool. Accounting for this response we ask how costly it is to secure that women be equally represented among those who win competitions. In particular, how much lower will the performance threshold be for women? How many better performing men will have to be passed by to hire a woman? To what extent will reverse discrimination arise? These questions are particularly interesting in light of the non-payoff maximizing tournament-entry decisions documented by NV.

We find that the introduction of affirmative action results in substantial changes in tournament entry. While the entry of women increases, that of men decreases, and the response exceeds that predicted by changes in the probability of winning. We attribute the excessive response in the gender gap to three different factors. One is that the mere mention of affirmative action increases women's willingness to compete. The other two factors both relate to the fact that affirmative action makes the competition more gender specific. The requirement that at least one of two winners must be a woman implies that a woman will win the tournament if she is either the best performing woman in her group or among the top two performers in the group overall. In contrast a man will win the tournament if he is both the top performing man in his group and among the two best performers in the group overall. There appears to be two reasons why a more gender-specific competition affects behavior: first, participants hold different beliefs on relative performance within versus across gender, and

\footnotetext{
${ }^{5}$ The University Record, May 22, 2000, http://www.ur.umich.edu/9900/May22_00/8.htm.

${ }^{6}$ See e.g., Page, 2007.

${ }^{7}$ For example, corporations such as Ernst and Young, Goldman Sachs, IBM, and PricewaterhouseCoopers have all adopted substantial female retention and attraction programs (see e.g., The Economist, July 21, 2005).

${ }^{8}$ Affirmative action programs in the US have historically been of two forms: preferential treatment and quota.
} 
second, participants seem to view competition as either less intimidating or enjoyable when competing against groups where the opposite gender is more poorly represented. ${ }^{9}$

The substantial tournament-entry response to affirmative action has important implications when assessing the sacrifice in performance required to secure a more diverse group of winners. The costs of affirmative action depend on how much lower the minimum performance threshold will have to be to secure gender parity, compared to that found for a group in which gender is not taken into account. Ignoring the change in entry, it is anticipated that equal representation of women will result in a decrease in the minimum performance requirement for women and that many better performing men will be passed by. The change in tournament entry implies that women become better represented among the set of entrants, and in particular that more high performing women are in the applicant pool. Thus it becomes much less costly to achieve equal representation and the resulting minimum performance threshold is unchanged under affirmative action. We therefore find that when women shy away from competition and don't enter when it is payoff maximizing to do so, it need not be costly to use affirmative action to achieve a more diverse set of winners.

In the next section we discuss why affirmative action may alter the tournament-entry decisions of men and women. We then describe our experimental design which builds on that of NV and discuss how it helps us investigate the potential effects of affirmative action. We introduce our analysis by first showing that our basic results replicate those of NV. We then proceed by determining the extent to which we can account for the changes in tournament entry under affirmative action. Finally we conclude by examining how changes in tournament entry mitigate the costs anticipated from affirmative action.

\section{Potential Effect of AA on Gender GAP in Tournament ENTRY}

NV finds that the gender gap in tournament entry in part can be explained by men being more overconfident than women, and by men and women having different attitudes towards competitions. The central question in this paper is whether and how an institution such as affirmative action affects the gender gap in tournament entry. We consider a quota system where at least one of two winners must be a woman. There are several factors that may result

\footnotetext{
9 This argument is similar to that given for the benefits of single sex education for girls: it may be easier for girls to compete when competing against only girls (See Solnick, 1995, and Harwarth, Maline, and DeBra, 1997). See also Gneezy, Niederle and Rustichini (2003) for performance in single versus mixed sex competitions.
} 
in tournament entry changing with this system. We will discuss the most obvious ones and explain how our experiment is designed to account for them.

Factor 1. Change in the probability of winning: The direct effect of affirmative action is that it distorts the probability of winning the tournament in favor of women and against men. To the extent that participants respond to changes in incentives, tournament entry is expected to increase for women and decrease for men. To control for this effect we condition on the probability of winning.

Factor 2. Within-gender beliefs: The NV study documented a significant gender difference in overconfidence and showed that this difference helps explain the gender gap in tournament entry. A consequence of affirmative action is that the tournament-entry decision does not only depend on the individual's perception of rank within the whole group, but also on the perception of rank within their gender. Specifically, a woman should enter either if she thinks she is the best performing woman or among the top two performers overall. In contrast a man should enter if he thinks he is both the best performing man and among the top two performers overall. If participants hold different beliefs on relative performance within versus across gender then this may cause the gender gap in tournament entry to change under affirmative action. We elicit the participant's within-gender beliefs to determine if they differ across gender and how they may affect tournament entry.

Factor 3. Affirmative action context effect: Another reason why participants may respond differently to the affirmative-action tournament is that the mere mention of affirmative action may discourage men and encourage women to select the competitive compensation. To control for this possibility we examine compensation choices under the affirmative action rule when these choices do not require a future competitive performance.

Factor 4. Competing against own gender: Finally a factor that may influence the decision to enter and actively compete in an affirmative-action tournament is that the competition becomes more gender specific. For women the competition is no longer simply a competition against all other members of the group, but rather a competition against the other women in the group. If 
women do not generally shy away from competitions, but rather shy away from competing in mixed-gender groups, then their behavior may be quite different under affirmative action. ${ }^{10}$ Changes may also be seen for men as affirmative action implies that it is no longer sufficient to be among the top two performers overall, rather a man also needs to be the best performing man. Having controlled for Factors 1 through 3, we will ascribe any unexplained response to affirmative action as evidence that Factor 4 influences behavior. ${ }^{11}$

\section{EXPERIMENTAL DESIGN}

The experiment was conducted at the Harvard Business School, using students from the CLER subject pool. Our design builds on that of NV. One to three groups of 6 participants, three women and three men, participated in each session. The gender composition of the group was made clear to participants as they were seated in the laboratory, and they were shown who the other 5 members of their group were. A total of 14 groups participated in the experiment for a total of 42 men and 42 women. $^{12}$

Participants were asked to perform a real task under varying compensation schemes. The task was to add up sets of five 2-digit numbers. Participants were not allowed to use a calculator, but could use scratch paper. The numbers were randomly drawn and each problem was presented in the following way:

\begin{tabular}{|l|l|l|l|l|l|}
\hline 21 & 35 & 48 & 29 & 83 & \\
\hline
\end{tabular}

For each problem participants were asked to fill in the sum in the blank box. Once the participant submitted an answer on the computer, a new problem appeared jointly with information on whether the former answer was correct. ${ }^{13}$ A record of the number of correct and incorrect answers was kept on the screen. Participants had 5 minutes to solve as many problems as they could. A stop watch was shown at the front of the room via a projector and a buzzer would go off at the end of the 5 minutes. The participant's final score was determined

\footnotetext{
${ }^{10}$ Gneezy, Niederle and Rustichini (2003) find that women are as good as men at competing in single-sex but not in mixed-sex tournaments. Such differences are often emphasized by advocates of single-sex schooling. It may be that girls do not dislike competition per se, but rather that they dislike competing against boys. Thus girls in allgirl schools may be more competitive (see Harwarth, Maline and DeBra 1997 for an overview).

${ }_{11}$ This captures the possibility that men and women are more comfortable competing against women than men.

${ }^{12}$ In one session (two groups) the stop watch malfunctioned for the fourth task. This session is excluded from our analysis. The behavior and performance prior to the fourth task resemble those of the other sessions.

${ }^{13}$ The program was written using the software zTree (Fischbacher 2007).
} 
by the number of correctly solved problems. An attractive feature of this 5 -minute addition task is that it requires both skill and effort.

Participants were told that they had to complete six tasks of which one was randomly chosen for payment at the end of the experiment. By paying only for one task, we diminish the chance that decisions in a given task may be used to hedge against outcomes in other tasks. In addition to their payment for performance each participant also received a $\$ 10$ show-up fee, and an additional $\$ 5$ for completing the experiment. Participants were informed of the nature of a task only immediately before performing the task. While participants knew their absolute performance on a task, i.e., how many problems they solved correctly, they were not informed of their relative performance until the end of the experiment. The specific compensations and order of tasks were as follows. ${ }^{14}$

Task 1 - Piece Rate: Participants are given the 5-minute addition task and receive 50 cents per correct answer.

Task 2 - Tournament: Participants are given the 5-minute addition task. The two participants who provide the largest number of correct answers in the group each receive $\$ 1.50$ per correct answer. The other participants receive no payment.

In the next task participants also perform the five-minute addition task, but this time they select which of the two compensation schemes they want to apply to their future performance, piece rate or tournament. A participant with a given performance has higher expected earnings in the tournament when the probability of winning exceeds 33 percent. ${ }^{15}$ There are two reasons for presenting participants with the compensations prior to their choice, first it provides them with experience of both, and second it provides us with performance measures which enable us to determine whether men and women of equal performance make similar compensation choices.

Task 3 - Choice: Before performing the 5-minute addition task, participants select whether they want to be paid according to a piece rate, i.e., 50 cents per correct answer, or a

\footnotetext{
${ }^{14}$ In the event that there are ties in a competitive task the winner was chosen randomly among the high scorers.

${ }^{15}$ By paying the tournament winner per correct problem we avoid the issue of choosing a high enough fixed prize to ensure that even high-performing participants benefit from tournament entry.
} 
tournament. A participant who selects the tournament wins the tournament and receives $\$ 1.50$ per correct answer if the participant's task-3 score exceeds that of at least 4 of the other group members in task 2 , otherwise the participant receives no payment.

Winners of the task-3 tournament are determined by comparing their task-3 performance to the task-2 performance of the other group members, rather than others' task-3 performance. Thus, participants compete against the past performances of others. ${ }^{16}$ As emphasized by NV this has several advantages; first, participants are competing against competitive performances of others; second, the tournament-entry decision only depends on beliefs about ones relative performance, and not on the expected tournament-entry decisions of others; ${ }^{17}$ and third, a participant's choice does not impose any externalities on others. ${ }^{18}$ Effectively the task-3 decision is an individual-decision problem.

Next we examine entry into an affirmative-action tournament. We refer to this as an AA tournament. In the AA tournament at least one of the winners will be a woman. Having mentioned the group's gender composition at the experiment's beginning, we hope to isolate the effect of affirmative action.

Task 4 - Affirmative-Action Choice: Before performing the 5-minute addition task, participants select whether they want to be paid according to a piece rate, i.e., 50 cents per correct answer, or an AA tournament. A participant who selects the AA tournament receives $\$ 1.50$ per correct answer when winning the tournament, and $\$ 0$ otherwise. The two winners are the highest performing woman and the highest performer of the remaining 5 participants. Thus, a woman wins the AA tournament if her task-4 performance either exceeds the task-2 performance of the two other women in the group or exceeds that of at least four other group members. A man wins the AA tournament if his task-4 performance both exceeds the task-2 performance of the two other men in the group and exceeds that of at least four other group members.

\footnotetext{
${ }^{16}$ Many sports competitions are not performed simultaneously, e.g., downhill skiing.

${ }^{17}$ This secures that the gender composition and size of the competitive group is held constant across participants.

${ }^{18}$ Note that our design allows for the possibility that participants who enter the tournament all lose or all win. The absence of externalities helps us rule out that women avoid the competition to not decrease the chance that others win. For a discussion of possible gender differences in altruism see e.g., Andreoni and Vesterlund (2001), Eckel and Grossman (2002b), Croson and Gneezy (2004).
} 
As argued by NV there are several reasons why men and women may differ in their willingness to enter a competition. One explanation is that preferences for performing in a competitive environment may differ across gender. ${ }^{19}$ Other more general explanations are that women may have lower expectations about their relative ability, be more averse to risk, or more reluctant to be in an environment where they receive feedback on their relative performance. ${ }^{20}$ What distinguishes gender differences in preferences for competing from the more general differences, is that the former relies critically on the tournament-entry decision resulting in a subsequent competitive performance. The other explanations are more general, and should be present in other decisions as well. To jointly control for the role played by these three general factors we present participants with two additional environments which mimic the tournament-entry decisions in Task 3 and 4, without involving an actual competitive performance. Specifically we first ask participants to choose between a competitive and a noncompetitive compensation scheme for their past non-competitive task-1 piece-rate performance, thus a choice of tournament does not require participants to subsequently perform in a competition. As the potential thrill, anxiety or fear of performing in a competition is absent from this choice, this decision will control for the effect general factors, such as overconfidence, risk and feedback aversion, have on the compensation choice. Participants are reminded of their task-1 piece-rate performance prior to their compensation choice.

Task 5 - Submit Piece Rate to a Tournament: Participants do not have to perform in this task. They choose which compensation they want to apply to their past piece-rate performance: a 50-cent piece rate per correct answer or a tournament. A participant who enters the tournament receives $\$ 1.50$ per correct answer if the participant's task-1 piece-rate performance is among the two highest scores in the group, otherwise no payment is received.

\footnotetext{
${ }^{19}$ While the prospect of engaging in a competition may cause women to anticipate a psychic cost and deter them from tournaments, men may anticipate a psychic benefit and be drawn to them. Nurture as well as nature may cause women to be more reluctant to perform in a competition, see e.g., Daly and Wilson (1983), Campbell (2002), Ruble, Martin, and Berenbaum (2006), Gneezy, Leonard and List (2006).

${ }^{20}$ While individuals are found to be overconfident, men tend to be more overconfident than women (e.g., Lichtenstein, Fischhoff and Phillips, 1982, Beyer, 1990, Beyer and Bowden, 1997, and Niederle and Vesterlund, 2007). Thus men may be more likely to enter tournaments. Another dimension in which men and women are found to differ is in their attitudes towards risk (e.g., Eckel and Grossman, 2002a, Croson and Gneezy, 2004, Byrnes, Miller and Shafer, 1999). As tournaments involve uncertain payoffs attitudes towards risk are expected to affect compensation choices. Finally, men and women have been found to respond differently to feedback on relative performance (see e.g., Roberts and Nolen-Hoeksema, 1989, Dweck 2000). Since entering the tournament results in learning whether one won or lost the tournament feedback aversion may also influence entry.
} 
Finally, for participants' last task they are asked to make a similar decision in an AA tournament, that is, they decide whether they want to submit their piece-rate performance to an AA tournament. This decision serves as a control for general factors in the affirmative-action decision including the possibility that merely mentioning affirmative action results in an excessive response in behavior.

Task 6 - Submit Piece Rate to AA Tournament: Participants do not have to perform in this task. They choose which compensation scheme they want to apply to their past piece-rate performance: a 50-cent piece rate per correct answer or an AA tournament. A participant who selected the tournament receives $\$ 1.50$ per correct answer when winning the tournament, and $\$ 0$ otherwise. The two winners are the highest performing woman and the highest performer of the remaining 5 participants.

As in tasks 3 and 4 a participant's decision does not affect the earnings of any other participant, nor does it depend on the entry decisions of others. Thus tasks 5 and 6 are also individualdecision tasks.

Finally, at the end of the experiment participants were asked to guess their rank in the task-1 piece rate and task-2 tournament both within the whole group of 6 participants and within their own gender. Each participant picked a rank between 1 and 6 and between 1 and 3 , respectively, and was paid $\$ 1$ for each correct guess. ${ }^{21}$ This allows us to determine if beliefs on relative performance differ in single versus mixed gender groups, and whether such differences affect tournament entry.

We can use Task 1, 2, 3 and 5 and across gender beliefs to determine whether we replicate the NV findings. By comparing choices in task 3 and 4, we can then move on to examine the effect of affirmative action on the gender gap in tournament entry. Of particular interest is the extent to which such changes are caused by the affirmative-action competition being more gender specific (Factor 4), or if it is accounted for by factors that are not associated with the active competition. Such non-competitive factors involve changes in the probability of winning (Factor 1), the fact that under affirmative action the probability of winning depends

\footnotetext{
${ }^{21}$ In the event of ties in actual rank we counted every answer that could be correct as correct. For example, if the performance in the group was 10,10,11,12,13, 13 then an answer of sixth and fifth was correct for a score of 10 , and an answer of first and second was correct for a score of 13.
} 
both on across-gender beliefs and on within-gender beliefs (Factor 2), and that the mere mention of affirmative action may result in an exaggerated response to affirmative action (Factor 3). Performance in task 1 and 2 will help us control for changes in the probability of winning (i.e., Factor 1), within-gender beliefs serve as a test of Factor 2, and we can use choices in tasks 5 and 6 as a control for Factor 3.

\section{Gender Differences in Compensation Choices}

We start by characterizing the tournament-entry decisions prior to the introduction of affirmative action, to determine whether we replicate the findings of NV. Although the experimental designs are similar there are several dimensions in which the two studies differ. First, participants in this experiment were made aware that groups were gender balanced; this may have altered behavior if it led participants to expect that gender was a variable of interest. $^{22}$ Second, we examine groups of 6 individuals with 2 winners, rather than groups of four with one winner. Third, our return from winning is $\$ 1.5$ per problem, rather than $\$ 2$ per problem as in NV. Fourth, we use students from the Harvard Business School CLER lab subject pool, rather than the PEEL subject pool at the University of Pittsburgh. Finally, showup and completion fees were altered to follow common practice at CLER. ${ }^{23}$ Each or all of these factors have the potential of influencing behavior. We first describe entry decisions in the present study, and then show that despite differences we replicate the main results of NV.

\section{IV.A. Piece Rate and Tournament: Performance and Choice}

In both the piece rate and tournament we find significant gender differences in performance. The average number of correctly solved problems in the piece rate is 10.3 for women and 12.9 for men, and in the tournament it is 12.3 for women and 14.8 for men. Two-sided MannWhitney tests show that both of these differences are significant $(p=0.03$ and $p=0.06$, respectively). ${ }^{24}$ To assess the probability of winning the tournament we randomly create six-

\footnotetext{
${ }^{22}$ For example, women may experience "stereotype threat" if they believe there is a stereotype against them performing well in competition against men. This source of anxiety (conform to the stereotype and fail to compete successfully) may lead to higher instances of "choking under pressure" when performing a task (Steele 1997).

${ }^{23}$ Participants in Pittsburgh were given \$5 show-up fee and \$7 for completing the tasks.

${ }^{24}$ While the piece rate and tournament performances are highly correlated (spearman rank correlations of 0.62 for women and 0.79 for men), participants perform better under the tournament than the piece-rate (matched pair sign rank tests yield $p<0.01$ for each gender separately). The average increase however does not differ by gender (a
} 
person groups from the observed performance distributions and determine the 2 winners. Conditioning only on gender, the probability of winning is 43.2 percent for a man and 23.5 percent for a woman. ${ }^{25}$ Table I shows that conditional on performance the probability of winning however is similar for women and men. ${ }^{26}$

TABLE I

PROBABILITY OF WinNING TASK-2 TOURNAMENT CONDITIONAL ON TASK-2 PERFORMANCE

\begin{tabular}{lcccccccccccccccccc}
\hline \hline & 8 & 9 & 10 & 11 & 12 & 13 & 14 & 15 & 16 & 17 & 18 & 19 & 21 & 22 & 25 & 28 & 29 & 35 \\
\hline Women & 0 & 0.1 & 0.6 & 2.5 & 8.6 & 21.8 & 40.7 & 58.1 & 71.4 & 80.2 & 87.1 & 92.2 & -- & 96.2 & -- & -- & -- & -- \\
Men & 0 & 0.1 & 0.7 & 2.8 & 11.0 & 28.2 & 48.7 & 65.8 & 77.8 & 85.6 & 91.1 & -- & 96.6 & 98.1 & 99.2 & 99.6 & 99.9 & 100 \\
\hline \hline
\end{tabular}

Having experienced both the 50-cent piece rate and $\$ 1.50$ tournament, participants are asked which of the two compensation schemes they want to apply to their task-3 performance. The tournament results in higher expected earnings when the probability of winning exceeds 33 percent. As seen in Table I this corresponds to participants who solve 14 or more problems. If a participant's performance in task 3 is exactly as in task 2 , then 28.6 percent of the women and 50 percent of the men have higher expected earnings in the tournament. This predicted gender gap is significant (a two-sided Fisher's exact test yields $p=0.07$ ). Unless otherwise noted the reported test statistics henceforth refer to a two-sided Fisher's exact test

The actual gender gap in tournament entry is even greater than predicted: 31 percent of women and 73.8 percent of men select the tournament. This gender gap is significant $(p<$ $0.01)$ and greater than expected $(p=0.04)$. While men enter significantly more than predicted by their task-2 performance $(p=0.042)$, women do not $(p=1.0)$.

To compare entry decisions of women and men, we condition their choices on their probability of winning the tournament. ${ }^{27}$ We regress the compensation choice on the probability of winning the task-2 tournament and on the change in the probability of winning a

two-sided Mann-Whitney test yields $p=0.73$ ). This improvement in performance may be caused by learning or by the performance incentives in the tournament. Two results suggest that learning may play a prominent role. First, NV shows that tournament entry does not influence the participant's subsequent performance. Second, DellaVigna, Malmendier and Vesterlund (in progress) have participants perform six rounds of 3-minute tournaments, and find a significant increase in performance from round 1 to 2 , but not in subsequent rounds.

${ }^{25}$ Of the 14 task-2 tournaments with 2 winners each, 20 were won by men and 11 by women (three cases of ties).

${ }^{26}$ For any given performance level, say 15 for a woman, we draw 1,000,000 groups consisting of 3 men and 2 women, using the performance distribution of the 42 men and 42 women with replacement. We then calculate the woman's frequency of wins in this set of simulated groups.

${ }^{27}$ Prior to the affirmative action analysis it is largely inconsequential to condition on the probability of winning rather than actual performance, however this distinction is important when we study the AA tournament where the probability of winning conditional on performance differs by gender. 
task-2 tournament when using the task- 2 performance versus the task- 1 performance. ${ }^{28}$ Table II shows that while the probability of winning does not influence the likelihood of tournamententry for women, it does increase it for men. Pooling men and women and conditioning on the probability of winning, we find a significant gender gap of 36 percentage points. That is a man with a 33 percent chance of winning the tournament, and a 16 percentage point increase in the probability of winning with the tournament rather than the piece rate performance, would have a 36 percentage point lower chance of entering the tournament if he were a woman. ${ }^{29}$

TABLE II

PROBIT OF TOURNAMENT CHOICE

\begin{tabular}{lccc}
\hline \hline & \multicolumn{3}{c}{ Task-2 Performance } \\
& Men & Women & All \\
\hline Female & & & -0.36 \\
Probability of Winning & 1.37 & 0.39 & $(0.00)$ \\
& $(0.02)$ & $(0.26)$ & 0.79 \\
Change in Prob. of & -0.62 & -0.06 & -0.29 \\
Winning Tour. to PR & $(0.21)$ & $(0.88)$ & $(0.27)$ \\
\hline Observations & 42 & 42 & 84 \\
\hline \hline
\end{tabular}

Dependent variable: task-3 compensation choice (1-tournament and 0-piece rate). The table presents marginal effects evaluated at an individual (a man in the last column) with a 33 percent chance of winning the tournament and a change of 0.16 in the probability of winning when using the piece-rate performance in the tournament. $p$ values are in parenthesis.

A possible explanation for the gender difference in the decision to enter the tournament is that participants correctly anticipate a change in performance following their task-3 choice. However, a probit regression using performance in task 3 yields similar results. ${ }^{30}$

The gender gap in tournament entry is greatest among those with high performance. Of those who for a given task-2 performance have higher expected earnings in the tournament than piece rate, i.e., those solving 14 or more problems, we find a significant $(p<0.01)$ gender

\footnotetext{
${ }^{28}$ The change in the probability of winning the tournament when using the task-2 rather than task-1 performance is given by $\mathrm{p}_{\mathrm{T}}\left(\right.$ Task 2)- $\mathrm{p}_{\mathrm{T}}$ (Task 1$)$, where $\mathrm{p}_{\mathrm{T}}(x)$ denotes the probability of winning the tournament with a performance of $x$ (note $\mathrm{p}_{\mathrm{T}}(x)$ may differ by gender).

${ }^{29}$ The marginal effect is evaluated at the point where a participant is indifferent towards entering the tournament, i.e., the probability of winning is 33 percent. This corresponds to having a performance between 13 and 14. For these participants $\mathrm{p}_{\mathrm{T}}($ Task 2$)-\mathrm{p}_{\mathrm{T}}($ Task 1$)=0.16$ on average, thus we assess the marginal effect at this point.

${ }^{30}$ When using task-3 performance to determine the probability of winning we find a 41 percentage point $(p<$ 0.01 ) gender gap in tournament entry. The task-3 performance is highly correlated with that in task-2 (spearman rank correlations are 0.78 for women and 0.77 for men). The average increase in performance from task 2 is 0.5 for women, and this increase is not significant (matched pair signrank test yields $p=0.32$, t-test $p=0.17$ ). The improvement of 0.69 for men is significant (matched pair signrank test $p=0.06$, t-test $p=0.07$ ). The gender difference in the improvement is not significant $(p=0.35)$.
} 
difference in entry, with 100 percent of the men and 33.3 percent of the women entering. In contrast the gender gap is not significant $(p=0.25)$ among participants who based on the task-2 performance have lower expected earnings in the tournament. For this group 47.6 percent of the men and 30 percent of the women enter. ${ }^{31}$ From a payoff-maximizing perspective too few high-performing women enter the tournament.

\section{IV.B. Explanations for the Gender Gap in Tournament Entry}

What factors can account for the gender differences in tournament entry? As in NV we examine whether men are more overconfident than women and whether this explains why fewer women enter the tournament. Combined with beliefs we then use the decision to submit the piece-rate performance to a tournament (task 5) to distinguish between the role played by gender differences in preferences for performing in a competition, and the more general explanations such as gender differences in overconfidence, risk and feedback aversion.

We first determine whether men and women of equal performance have different beliefs about their relative task-2 tournament performance. ${ }^{32}$ As men outperform women we cannot directly compare beliefs across gender. Instead we compare beliefs conditional on the participant's optimal guessed rank. A participant's optimal guessed rank is the rank that conditional on gender and performance would maximize earnings from guessing. ${ }^{33}$ Not surprisingly the optimal guessed ranks of women and men are significantly different (twosided Mann-Whitney $p=0.05$ ). Ordered probit regressions show that women and men with a higher performance and thereby a higher optimal guessed rank believe they have a higher rank. $^{34}$ This result is illustrated by Figure 1 which shows the participants' guessed rank conditional on the optimal guessed rank. While men are overconfident, women are not. ${ }^{35}$ Controlling for optimal guessed rank, men are more optimistic about their relative performance

\footnotetext{
${ }^{31}$ The results are practically identical when using task-3 performance.

${ }^{32}$ Recall we paid participants $\$ 1$ to correctly guess how their performance ranked relative to the other members of their group. A strong positive correlation between elicited ranks and tournament entry (Table III) suggests that hedging against the tournament-entry decision was not a dominant motive when reporting beliefs.

${ }^{33}$ For a given performance level, say 15 for a woman, we draw $1,000,000$ groups consisting of 3 men and 2 women, sampling with replacement from the performance distribution of the 42 men and 42 women. We then determine the woman's rank in each of these groups and the optimal guessed rank is the mode of these ranks.

${ }^{34} \mathrm{An}$ ordered probit regression of guessed tournament rank on optimal guessed rank yields a coefficient of 0.42 for men and 0.34 for women, each with $p<0.01$.

${ }^{35}$ For men, testing if the distribution of guessed ranks is independent of that of actual ranks yields $p=0.09$, and comparing the distribution of guessed rank to optimal ranks yields $p=0.04$. For women, the comparisons of guessed ranks to actual ranks yields $p=0.51$ and to optimal guessed ranks yields $p=0.37$.
} 
than women. An ordered probit regression of the guessed tournament rank yields coefficients of 0.39 on the optimal guessed rank $(p<0.01)$ and 0.66 on a female dummy $(p=0.01)$.

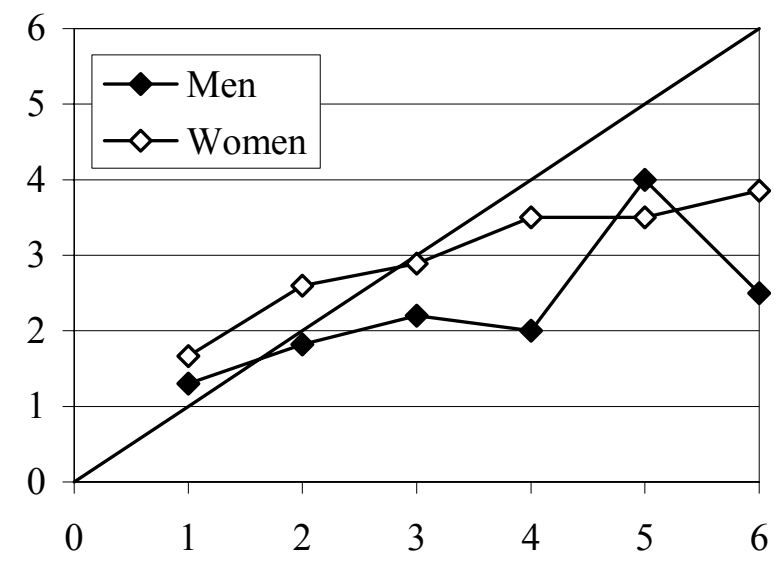

FIGURE I: The mean guessed rank for each optimal guessed rank

A method for summarizing beliefs which will prove helpful in our affirmative action analysis is to consider whether the participant's guessed rank is consistent with the belief that he or she will win the tournament, we refer to this measure as GuessWin. ${ }^{36}$ The results on beliefs are very similar when we use this binary belief measure, and the correspondingly constructed optimal guessed-win measure. Those who are most likely to win are also more likely to report beliefs consistent with winning, and conditional on optimal guessed win, men are significantly more likely than women to believe that they will win. ${ }^{37}$ While men are overconfident, women are not. ${ }^{38}$

Next we examine the extent to which the overconfidence of men can explain why conditional on performance men enter the tournament more frequently than women. Although entry decisions are positively correlated with the participants' beliefs on winning the tournament, there are still substantial gender differences. ${ }^{39}$ Looking at the 54 percent of

\footnotetext{
${ }^{36}$ While the AA tournament entry decision conditional on GuessWin is predicted to be the same for men and women that is not the case when conditioning on guessed rank.

${ }^{37}$ A probit regression of the guess of winning the tournament yields marginal coefficients of -0.3 on female $(p=$ $0.01)$, and 0.45 on optimal guess of winning $(p<0.01)$, evaluated at a man whose optimal guess is winning.

${ }^{38}$ For men, testing if the distribution of GuessWin is independent of actual win yields $p=0.05$, and a comparison of GuessWin to OptimalGuessWin yields $p=0.07$. For women, the comparison of GuessWin to actual win yields $p=0.64$ and to optimal win $p=0.48$. For women, the marginal coefficient of a probit regression of the guess on winning the tournament on OptimalGuessWin yields a coefficient of $0.32(p=0.06)$ on someone whose optimal guess is to win. For men the coefficient is $0.48(p<0.01)$.

${ }^{39}$ A probit regression of the propensity to enter the tournament as a function of the guess of winning the task-2 tournament yields, for men: $0.45(p<0.01)$, and for women $0.45(p<0.01)$.
} 
participants' who have beliefs consistent with winning the task-2 tournament, 87 percent of men enter the tournament, compared to 60 percent of women. Among the remaining participants whose beliefs are consistent with loosing the task-2 tournament, 42 percent of men enter the tournament, compared to 15 percent of women. While the gender gap is around 27 percentage points in both cases, the difference is only significant among those who believe that they will win ( $p=0.06$ and $p=0.10$, respectively).

The probit regression of Table III shows tournament entry as a function of both absolute and believed performance. When only controlling for performance the gender gap was 36 percentage points (Column 1). This gap reduces to 25 percentage points when we control for the participants' imputed beliefs on winning the tournament. ${ }^{40}$ Although the overconfidence by men helps account for the gender difference in tournament entry a substantial portion of the gap remains unexplained.

\section{TABLE III}

\section{PROBIT OF TOURNAMENT-ENTRY DECISION (TASK 3):}

\begin{tabular}{lcc}
\hline \hline & $(1)$ & $(2)$ \\
\hline Female & -0.36 & -0.25 \\
& $(0.00)$ & $(0.03)$ \\
Probability of Winning & 0.79 & 0.45 \\
& $(0.00)$ & $(0.02)$ \\
Change in Prob. of Winning Tour. to PR & -0.29 & -0.31 \\
& $(0.27)$ & $(0.15)$ \\
GuessWin & & 0.35 \\
& & $(0.01)$ \\
\hline Observations & 84 & 84 \\
\hline \hline
\end{tabular}

Dependent variable: task-3 compensation choice (1-tournament and 0-piece rate). The table presents marginal effects evaluated at a man with a 33 percent chance of winning the tournament, and a 0.16 change in the probability of winning from a piece-rate to a tournament, who thinks that he would win the tournament (i.e., ranks either first or second in his group of six) in column 2. $p$-values are in parenthesis.

To account for the unexplained gap in tournament entry we use the elicited beliefs and task-5 compensation choice to simultaneously control for the role played by gender differences in general factors such as overconfidence, risk and feedback aversion. In task 5 participants choose between a competitive and a non-competitive compensation scheme for their past task1 piece-rate performance. This decision is similar to the decision to enter a tournament and perform in a competition (task 3). The difference between the two is that only in task 3 do they subsequently have to compete. Thus while overconfidence, risk and feedback aversion can

\footnotetext{
${ }^{40}$ When we use belief on rank instead of GuessWin, the marginal coefficient on female in the probit regression is reduced to $-0.18(p=0.04)$.
} 
influence the compensation choices in task 3 and 5, only in task 3 can differences in preferences for performing in a competition play a role. ${ }^{41}$

Controlling both for the task-5 decision and the elicited beliefs we determine if the act of performing in a competition creates a gap in tournament entry that cannot be explained by these general factors. As seen in Table IV the effect of controlling for the task-5 decision is substantial. While adding beliefs reduced the gender gap in tournament entry from 36 to 25 percentage points (Columns 1 and 2), the gender gap is further reduced to 17 percentage points when controlling for the decision to submit the piece rate (Column 3). This decrease may be explained both by the control for risk and feedback aversion, and by the fact that the decision to submit the piece rate serves as an additional measure of the individual's general degree of confidence. It is therefore not surprising to see that the coefficient on GuessWin decreases as we move from Column 2 to Column $3 .^{42}$ Despite the explanatory power of these variables a substantial gender gap in tournament entry remains. The remaining gap suggests that the decision to enter the tournament is explained in part by women being relatively more averse to choices that require a future performance in a competitive environment.

\begin{tabular}{lccc}
\multicolumn{4}{c}{ TABLE IV } \\
Probit OF TOURNAMENT-ENTRY DECISION & $($ TASK 3) \\
\hline \hline & $(1)$ & $(2)$ & $(3)$ \\
\hline Female & -0.36 & -0.25 & -0.17 \\
& $(0.00)$ & $(0.03)$ & $(0.04)$ \\
Prob. Of Winning & 0.79 & 0.45 & 0.22 \\
& $(0.00)$ & $(0.02)$ & $(0.08)$ \\
Change in Prob. of Winning Tour. to PR & -0.29 & -0.31 & -0.11 \\
& $(0.27)$ & $(0.15)$ & $(0.45)$ \\
GuessWin & & 0.35 & 0.25 \\
& & $(0.01)$ & $(0.01)$ \\
Submit the Piece Rate & & & 0.15 \\
& & & $(0.10)$ \\
\hline Observations & 84 & 84 & 84 \\
\hline \hline
\end{tabular}

Dependent variable: task-3 compensation choice (1-tournament and 0-piece rate). The table presents marginal effects evaluated at a man with a 33 percent chance of winning, a 0.16 change in probability of winning, who submitted his piece rate to the tournament (column 3), and thinks (columns 2 and 3) that he wins the tournament (i.e., ranks first or second in his group of six). $p$-values are in parenthesis.

\footnotetext{
${ }^{41} \mathrm{An}$ indication of the differences between task 3 and task 5 is that conditional on the probability of winning a task-1 tournament there are no gender differences in task- 5 decisions.

${ }^{42}$ When we use the belief on rank instead of GuessWin, the marginal coefficient on female is $-0.15(p=0.04)$. Thus controlling for the task- 5 decision only yields a minor reduction in the gender gap in tournament entry.
} 


\section{IV.C. Comparison to NV}

Although there are several differences between this study and that of NV, the overall findings are nonetheless similar. While NV found no significant gender differences in performance, in the present study men on average outperform women by 2.5 problems in both the piece rate and the tournament. Interestingly the female performance in the present study is in line with that of $\mathrm{NV}$, where on average men and women solve 10.4 problems in the piece rate and 12 problems in the tournament. ${ }^{43}$ The gender differences in tournament entry are, however, similar in the two studies. In NV the gender gap in tournament entry is 38 percentage points when controlling only for the probability of winning the tournament. Controlling also for the participant's belief on winning the task-2 tournament this gap reduces to 26 percentage points, and finally adding the decision to submit the piece rate to a tournament reduces the gap to 14 percentage points. In comparison the present study finds that the corresponding gender gaps are 36,25 , and 17 percentage points. ${ }^{44}$ Thus the results of $\mathrm{NV}$ are both qualitatively and quantitatively similar to those found here. The only difference between the two studies is that while NV finds that low-performing men enter the tournament more often than low-performing women, this difference is not significant in the present study. ${ }^{45}$

\section{The EFFECT Of AfFirmative ACTION ON ENTRY}

Next we examine the response to the affirmative action requirement that at least one of two winners must be a woman. In determining the role played by the factors presented in Section II we first account for changes in the probability of winning. We then examine the effect of beliefs and pay particular attention to the comparison of within- versus across-gender beliefs. To account for the effect of merely mentioning affirmative action, we compare the decisions to submit a past piece-rate performance to a standard versus an AA tournament (task 5 vs. 6). Finally, using both beliefs and the decision to submit the piece rate we determine whether the effect of affirmative action on tournament entry in part can be explained by participants having to perform in a more gender-specific competition.

\footnotetext{
${ }^{43}$ Our design does not enable us to determine what causes this gender gap in performance, in particular we can not determine if it is caused by participants knowing that gender is a variable of interest.

${ }^{44}$ To conform to the present study we reran the regression in NV including all participants and controlling for the probability of winning and participants' GuessWin. The reported numbers differ slightly from those of NV.

${ }^{45}$ Subsequent experiments at Harvard suggest that this difference is significant in a second sample, and when using the larger combined sample (Niederle, Segal, Vesterlund, in preparation).
} 


\section{V.A. The Effect of Changes in the Probability of Winning on AA Tournament Entry (Task 4)}

The introduction of affirmative action increases the probability of winning the tournament for women while decreasing it for men. If participants in an AA tournament had performances as in task 2 then the predicted probabilities of winning would be 36.2 percent for women and 30.4 percent for men. Conditioning on both gender and individual performance the probabilities of winning the AA tournament are as reported in Table V.

\section{TABLE V}

PROBABILITY OF WINNING TASK-4 TOURNAMENT CONDITIONAL ON TASK-2 PERFORMANCE:

\begin{tabular}{lccccccccccccccccc}
\hline \hline & 9 & 10 & 11 & 12 & 13 & 14 & 15 & 16 & 17 & 18 & 19 & 21 & 22 & 25 & 28 & 29 & 35 \\
\hline Women & 1.8 & 4.9 & 10.5 & 25.3 & 46.9 & 64.6 & 77.3 & 85.7 & 91.1 & 94.7 & 97.3 & -- & 99.3 & -- & -- & -- & -- \\
Men & 0.1 & 0.4 & 1.6 & 5.5 & 14.2 & 26.8 & 39.6 & 50.6 & 58.6 & 66.8 & -- & 75.3 & 79.6 & 84.0 & 88.5 & 93.0 & 97.6 \\
\hline \hline
\end{tabular}

As noted earlier, anyone with a 33 percent or higher chance of winning the tournament has higher expected earnings from the tournament than piece rate. Thus, as seen in Table V, women with a performance of 13 or more and men with a performance of 15 or more are in expectation better off selecting the AA tournament. Affirmative action therefore decreases the performance at which it becomes profitable to enter the tournament by one correct problem for women while increasing it by one correct problem for men. ${ }^{46}$

If participants' task-4 performance is as their task-2 performance, then it is payoff maximizing to enter the AA tournament for 40.5 percent of women and 38.1 percent of men. In sharp contrast, we observe 83.3 percent of women and 45.2 percent of men entering, while the entry by women is greater than predicted that by men is not $(p<0.01$ and $p=0.66$, respectively). The resulting gender gap in entry into the AA tournament is significant ( $p<$ $0.01)$ and differs from that predicted $(p<0.01) .{ }^{47}$ Entry in the AA tournament therefore contrasts with that of the standard tournament. While men in the standard tournament enter more than predicted and more than women, this result is reversed under affirmative action as women enter more than predicted and more than men.

To assess how changes in the probability of winning affect tournament entry, we compare entry decisions under the standard and AA tournament. Figure II panel A shows the proportion of men who enter the standard and AA tournament conditional on their probability

\footnotetext{
${ }^{46}$ Using the task-2 performance distribution five more women and five fewer men should enter the tournament.

${ }^{47}$ We calculate the difference between expected and actual gender gaps in AA tournament entry decision for $1,000,000$ simulations where we draw the 42 women and 42 men with replacement (using thresholds implied by Table V). The reported p-value is the percentage of strictly positive differences.
} 
of winning each tournament. Panel B shows the corresponding figure for women. Both figures use performance prior to the entry decision (i.e., task 2) to determine the probability of winning, the figures are similar if we instead use ex-post performance (i.e., task 3 and 4). If changes in tournament entry were solely driven by changes in the probability of winning, then the two propensities to compete should coincide for the standard and AA tournaments.

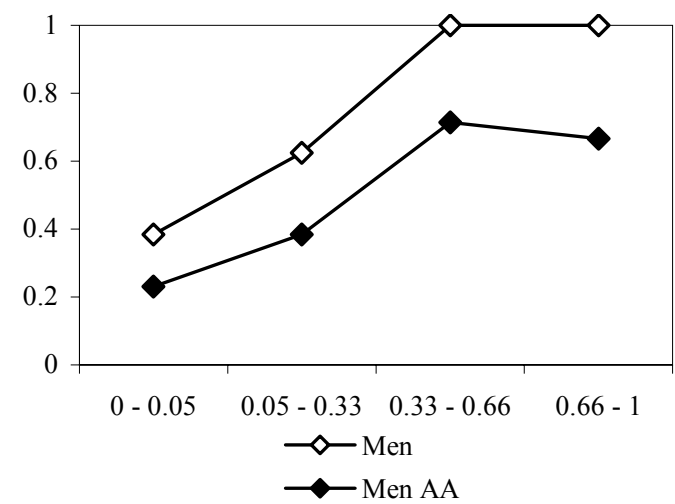

Panel (A)

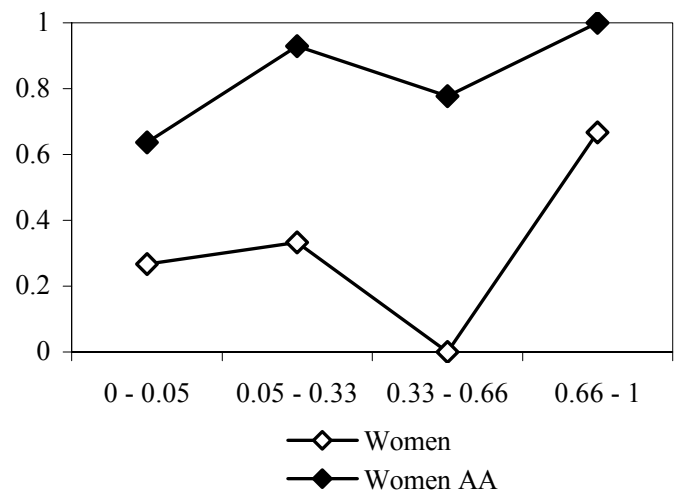

Panel (B)

FIGURE II: Proportion of participants entering the standard or the AA tournament conditional on probability of winning the tournament given ex-ante performance (task 2). ${ }^{48}$

Figure II shows that affirmative action reduces tournament entry by men beyond what is warranted by changes in the probability of winning the tournament. The overreaction by women appears even greater, as they are much more likely to compete under affirmative action. This finding is confirmed by a probit regression of the decision to enter a tournament on the probability of winning as well as an affirmative-action dummy (Table VI). For each individual we use both the decision to enter the task-3 tournament, and the decision to enter the task-4 AA tournament. We condition the tournament-entry decision on the probability associated with winning the tournament in question and cluster on the participant to account for the lack of independence between the two individual observations. If entry decisions by women and men depend solely on the probability of winning the tournament, then the marginal coefficient on the affirmative action dummy (AA) should be zero. Consistent with Figure II we

\footnotetext{
${ }^{48}$ The bin size was chosen to secure similar numbers of participants in each bin. The number of individuals in each bin is as follows: In panel $\mathrm{A}$, in the standard tournament there are $13,8,8$, and 13, in each of the four bins with 13 in 0-0.05. In the AA tournament there are 13, 13, 7, and 9. In panel B, in the standard there are 15, 15, 6, and 6 , and in AA there are $11,14,9$, and 8 .
} 
see that the effect of affirmative action on entry is negative for men, and positive for women. ${ }^{49}$ Similarly, as seen by the significant female and affirmative-action interaction in the pooled regression, changes in the probability of winning do not fully account for the change in the gender gap under affirmative action.

TABLE VI

PROBIT OF TOURNAMENT CHOICE

\begin{tabular}{lccc}
\hline \hline & \multicolumn{3}{c}{ Task 2 Performance } \\
\hline Female & Men & Women & All \\
Female*AA & & & -0.37 \\
& & & $(0.00)$ \\
AA & & & 0.26 \\
& -0.29 & 0.51 & -0.27 \\
Prob. of Winning & $0.01)$ & $(0.00)$ & $(0.01)$ \\
& 0.90 & 0.28 & 0.64 \\
Change in Prob. of Winning Tour. to PR & $(0.00)$ & $(0.28)$ & $(0.00)$ \\
& -0.35 & 0.30 & -0.09 \\
Observations & $(0.22)$ & $(0.25)$ & $(0.61)$ \\
\hline \hline
\end{tabular}

The table presents marginal effects evaluated at an individual (a man in the last column) in the standard tournament, with a probability of winning of 0.33 and a change in the probability of winning of 0.16 . We cluster on participant to account for there being 2 observations for each of the 84 participants. $p$-values are in parenthesis.

\section{V.B. Do Beliefs Explain Changes in Tournament Entry under AA?}

In the standard tournament we found that conditional on optimal guessed rank, men were significantly more optimistic about their relative performance than women, and this difference helped explain the gender gap in tournament entry. If participants' beliefs on winning are similar in the AA and standard tournament then it is unlikely that beliefs will help explain the response to affirmative action.

We first analyze beliefs on within-gender rankings in task-2. For women and men we calculate the guess which would be money-maximizing given individual performance. Neither

\footnotetext{
${ }^{49}$ The result is the same if we condition on the probability of winning after the entry decision, i.e., on task 3 and 4. Both women and men improve their performance from task 2 to task 4 , however there is no gender difference in the improvement $(p=0.95)$. The improvements in performance are 0.62 for women and 0.83 for men (matched pair signrank tests $p=0.04$ and 0.05 respectively). The improvement in performance does not vary by task- 4 choice ( $p=0.91$ if enter, $p=0.36$ if piece rate), nor is there a difference when conditioning on gender and task- 4 choice $(p \geq 0.35)$. The improvement in performance is primarily driven by an increase in performance between task 2 and 3. The improvement between task 3 and 4 is not significant and equals 0.12 for women and 0.14 for men (matched pair signrank test yields $p=0.79$ and 0.97 , respectively). Neither men nor women who enter the tournament have a significantly different improvement in performance in task 4 relative to task $3(p \geq 0.14)$.
} 
women nor men seem overconfident. The distributions of guessed ranks within gender are not significantly different from actual or optimal guessed rank $(p=0.60$ and $p=0.21$ for women, and $p=0.45$ and $p=0.45$ for men, respectively). ${ }^{50}$ Ordered probit regressions confirm that the guessed ranks within gender are correlated with optimal guesses, and that there is no gender difference in beliefs on relative tournament performance within one's gender. That is, women seem as confident in their relative performance among women, as men do among men. ${ }^{51}$

While men are significantly more confident than women when assessing relative ability in a mixed-gender group, there is no gender difference within gender. Figure III shows for each optimal guessed rank the average guessed rank of women and men. Panel A shows the rankings among all 6 participants, while Panel B shows rankings within one’s gender.

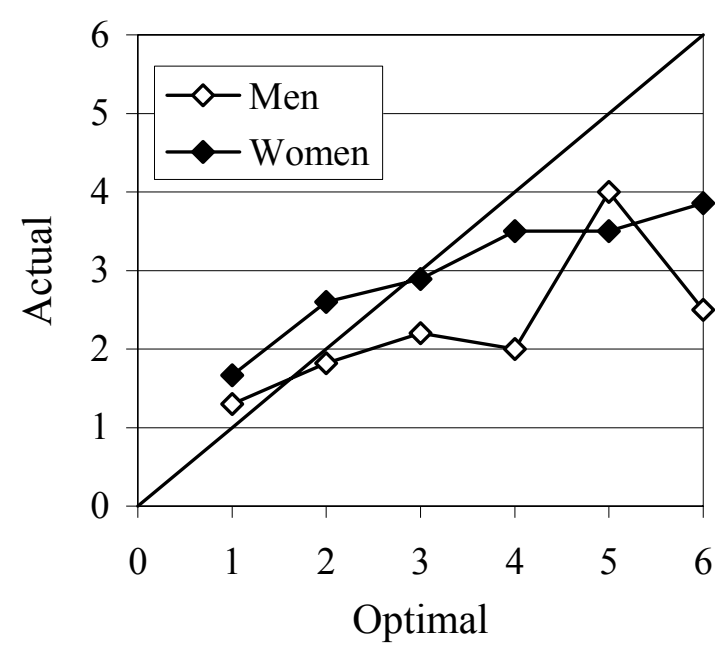

Panel (A)

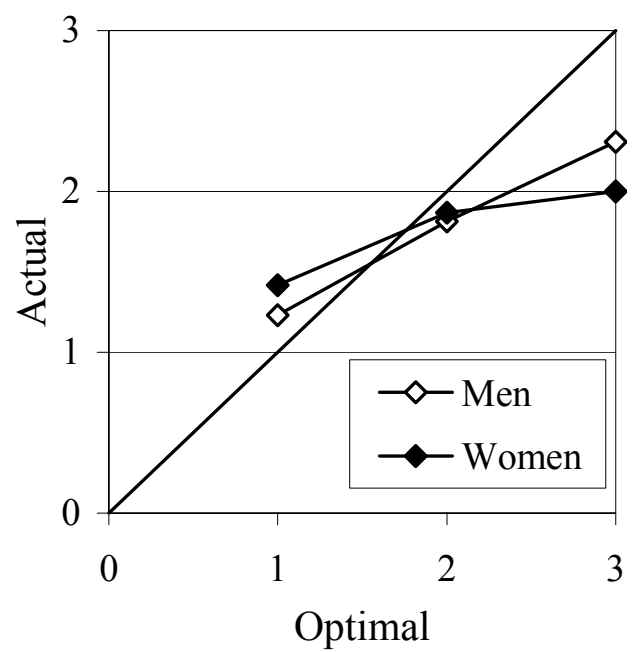

Panel (B)

Figure III: Average guessed rank as a function of optimal tournament rank in the whole group of 6 participants (A), and among group members of one's gender (B).

To evaluate the impact of beliefs on the more gender-specific AA tournament, we construct participants' beliefs on whether they would have won the task-2 tournament under AA rules (GuessAAWin). Recall that a woman wins the AA tournament if she is either the best performing woman or among the two best performing participants in the group. A man, on the other hand, wins the AA tournament if he is both the best performing man and among the

\footnotetext{
${ }^{50}$ The actual rank corresponds to the highest actual rank possible in case of ties The distributions of optimal and actual rank within gender do not differ $(p=0.74$ for men and $p=1.0$ for women).

${ }^{51}$ An ordered probit regression of guessed rank on optimal rank within gender yields coefficients for men of 0.99 $(p<0.01)$, and $0.46(p=0.04)$ for women. Pooling all 42 women and 42 men yields coefficients of -0.04 on a female dummy $(p=0.87)$, and 0.70 on optimal rank $(p<0.01)$.
} 
top two performers overall. We compare GuessAAWin both to the actual outcomes as well as to the belief on winning that is consistent with the participant's optimal guessed rank. We refer to this measure as OptimalGuessAAWin. Similar to our guessed-rank results within gender, for GuessAAWin we find that neither women nor men are overconfident. ${ }^{52}$ Furthermore, we find no gender differences in GuessAAWin when conditioning on OptimalGuessAAWin. ${ }^{53}$ This result contrasts that of the standard tournament where conditional on OptimalGuessWin, men are significantly more likely than women to believe that they will win. As expected we find that relative to the standard tournament fewer men think that they will win the AA tournament, whereas more women think they will win the AA tournament. Note however that this change is only significant for men. ${ }^{54}$

To determine the impact of beliefs on changes in tournament entry under affirmative action we condition on the guess-win measures, see Table VII. The advantage of using the GuessWin measures is that it incorporates the differences between the standard and AA tournament, and accounts for the gender specific incentives. Controlling for performance we see in the first four columns that individuals who have beliefs consistent with winning are more likely to enter the tournament, however in a two-sided test this effect is only significant for women. Nonetheless, as seen by the coefficient on the AA dummy, for both men and women, including beliefs on winning reduces the change in the propensity to enter a tournament with affirmative action by about 20 percent.

\footnotetext{
${ }^{52}$ On average the guessed AA win is not significantly different from actual AA win $(p=0.50$ for men, and $p=$ 0.51 for women), or the optimal guess AA win ( $p=1.0$ for men and $p=0.49$ for women).

${ }^{53}$ A probit regression of guess AA win for the 84 participants delivers the following marginal effects evaluated at a man with an optimal guess of winning: 0.08 on female $(p=0.43) ; 0.40$ on optimal guess AA win $(p<0.01)$. Examining men and women separately yields coefficients on optimal guess AA win of $0.53(p<0.01)$ for men, $0.27(p=0.12)$ for women. Furthermore, there are no significant gender differences in distributions of optimal guesses $(p=1.0)$, actual chances of winning $(p=0.65)$, nor guessed AA win $(p=0.66)$.

${ }_{54}$ In the standard tournament 30 men $(70 \%)$ guess they win the tournament, compared to $17(40.5 \%)$ in the AA tournament. The numbers for women are $15(35.7 \%)$ in the standard and $20(47.6 \%)$ in the AA tournament. The marginal effects of a clustered probit regression of GuessWin (standard or AA) evaluated for someone in the standard tournament who should optimally guess they win are for men: $0.40(p<0.01)$ on optimal guess and -0.15 $(p<0.01)$ on AA dummy. For women the coefficients are $0.36(p=0.03)$ and $0.08(p=0.10)$ respectively. A pooled regression shows a significant gender difference in the response to affirmative action, the marginal coefficient on a female and AA interaction is $0.06(p=0.00)$, when controlling for optimal guesses, AA and female, and evaluating coefficients at a man in the standard tournament whose optimal belief is to win.
} 
TABLE VII

PROBIT OF TOURNAMENT CHOICE

\begin{tabular}{lcccccc}
\hline & Men & Men & Women & Women & All & All \\
\hline Female & & & & & -0.37 & -0.29 \\
& & & & & $(0.00)$ & $(0.01)$ \\
Female*AA & & & & & 0.26 & 0.18 \\
& & & & & $(0.00)$ & $(0.00)$ \\
AA & -0.29 & -0.23 & 0.51 & 0.40 & -0.27 & -0.18 \\
& $(0.01)$ & $(0.04)$ & $(0.00)$ & $(0.00)$ & $(0.01)$ & $(0.07)$ \\
Prob. Of Winning & 0.90 & 0.70 & 0.28 & 0.06 & 0.64 & 0.40 \\
& $(0.00)$ & $(0.00)$ & $(0.28)$ & $(0.83)$ & $(0.00)$ & $(0.00)$ \\
Change Prob. Winning & -0.35 & -0.38 & 0.30 & 0.23 & -0.09 & -0.15 \\
Tour. To PR & $(0.22)$ & $(0.15)$ & $(0.25)$ & $(0.41)$ & $(0.61)$ & $(0.31)$ \\
GuessWin & & 0.19 & & 0.38 & & 0.27 \\
& & $(0.16)$ & & $(0.00)$ & & $(0.00)$ \\
\hline Observations & 84 & 84 & 84 & 84 & 168 & 168 \\
\hline \hline
\end{tabular}

The table presents marginal effects evaluated at an individual (a man in the last two columns), in the standard tournament, with a 0.33 percent probability of winning and a change in the probability of winning of 0.16 , with a guess of winning (in columns 2, 4, and 6). We cluster on the participant to account for there being 2 observations for each of the 84 participants. $p$-values are in parenthesis.

GuessWin is also significant in the pooled regression. Thus the change in the gender gap is in part explained by men being overconfident about their relative performance in mixed-gender groups, and less so in more gender-specific groups. However controlling for beliefs the coefficient on the female and affirmative-action interaction remains significant, indicating that changes in the gender gap in tournament entry under affirmative action is not fully explained.

\section{V.C. Effects of Submitting the Piece-Rate Results}

Next we examine the decisions to submit the piece rate to a standard or AA tournament. This analysis helps determine whether merely mentioning affirmative action influences behavior, and whether the response to affirmative action may result from the AA tournament requiring performance in a more gender-specific competition.

We first compare the decisions to submit the piece rate to the standard versus the AA tournament (task 5 vs. 6). Affirmative action will affect the decision to submit the piece rate through changes in the probability of winning, differences in beliefs between mixed- versus single-gender groups, and the effect of mentioning affirmative action. The probit regression in table VIII shows that controlling both for beliefs and the probability of winning, the introduction of affirmative action does not cause men to change their decision to submit a piece-rate result to a tournament, the coefficient on the AA dummy is very small and at best 
marginally significant. Women on the other hand are 28 percentage points more likely to submit their piece-rate performance when we introduce affirmative action. In the pooled analysis, the coefficient on the female and affirmative-action interaction is significant, demonstrating that the gender gap in submitting the piece rate differs significantly between the standard and AA tournament. These findings suggest that while simply mentioning affirmative action does not affect men, it does affect women.

TABLE VIII

PRobit OF Submitting THE Piece RATE

\begin{tabular}{lccc}
\hline \hline & Men & Women & All \\
\hline Female & & & -0.17 \\
& & & $(0.11)$ \\
Female*AA & & & 0.10 \\
& & & $(0.00)$ \\
AA & -0.04 & 0.28 & -0.06 \\
& $(0.12)$ & $(0.00)$ & $(0.17)$ \\
Prob. of Winning & 0.04 & 0.35 & 0.17 \\
& $(0.52)$ & $(0.096)$ & $(0.06)$ \\
GuessWin & 0.83 & 0.55 & 0.72 \\
& $(0.00)$ & $(0.00)$ & $(0.00)$ \\
\hline Observations & 84 & 84 & 168 \\
\hline \hline
\end{tabular}

The marginal effects are evaluated at an individual (a man in the last column), in the standard tournament, with a probability of winning of 0.33 , with a guess of winning. We cluster on the participant to account for there being 2 observations for each of the 84 participants. $p$-values are in parenthesis.

Although the decisions to submit the piece rate and entering the tournament are very similar the difference between them is that in the first case a tournament choice does not result in a subsequent competitive performance. Thus the effect of affirmative action observed between task 5 and 6 cannot be driven by participants having different attitudes toward competing in groups where members of the opposite gender are more poorly represented. That is, in contrast to the difference between task 3 and 4, changes in compensation choices between task 5 and 6 cannot be explained by say women being more eager to compete in single- rather than mixed-gender groups. To determine whether the effect of affirmative action in part is explained by the competition being more gender specific, we use the task 5 and 6 decisions as controls in the task 3 and 4 decisions.

Table IX examines changes in the decision to enter a tournament under affirmative action, when we control for the probability of winning, beliefs, and the decision to submit the piece-rate to a tournament. Conditioning on these factors affirmative action decreases the 
probability that a man enters a tournament by 9 percentage points. This remaining effect may represent the reduction in the thrill of competing against a group with greater male representation. For women, the remaining effect of affirmative action is a 25 percentage point increase in tournament entry. Pooling men and women we see that the decision to submit the piece rate to the AA tournament helps explain the change in the gender gap, however the female and affirmative action interaction remains significant. Thus the gender gap in tournament entry differs significantly between the AA and standard tournament. ${ }^{55} \mathrm{We}$ ascribe this remaining difference to the competition being more gender specific under affirmative action. Men may feel more pressure to compete when the fraction of male competitors increase, whereas the fear of competing may diminish when women are in all female groups.

TABLE IX

PROBIT OF TOURNAMENT CHOICE

\begin{tabular}{lccccccccc}
\hline \hline & Men & Men & Men & Women & Women & Women & All & All & All \\
\hline Female & & & & & & & -0.37 & -0.29 & -0.18 \\
& & & & & & & $(0.00)$ & $(0.01)$ & $(0.02)$ \\
Female*AA & & & & & & & 0.26 & 0.18 & 0.07 \\
& & & & & & & $(0.00)$ & $(0.00)$ & $(0.00)$ \\
AA & -0.29 & -0.23 & -0.09 & 0.51 & 0.40 & 0.25 & -0.27 & -0.18 & -0.09 \\
& $(0.01)$ & $(0.04)$ & $(0.09)$ & $(0.00)$ & $(0.00)$ & $(0.00)$ & $(0.01)$ & $(0.07)$ & $(0.11)$ \\
Prob. Of Winning & 0.90 & 0.70 & 0.19 & 0.28 & 0.06 & -0.09 & 0.64 & 0.40 & 0.13 \\
& $(0.00)$ & $(0.00)$ & $(0.01)$ & $(0.28)$ & $(0.83)$ & $(0.71)$ & $(0.00)$ & $(0.00)$ & $(0.03)$ \\
Change Prob. Winning & -0.35 & -0.38 & 0.01 & 0.30 & 0.23 & 0.43 & -0.09 & -0.15 & 0.06 \\
Tour. To PR & $(0.22)$ & $(0.15)$ & $(0.92)$ & $(0.25)$ & $(0.41)$ & $(0.11)$ & $(0.61)$ & $(0.31)$ & $(0.42)$ \\
GuessWin & & 0.19 & 0.05 & & 0.38 & 0.35 & & 0.27 & 0.12 \\
& & $(0.16)$ & $(0.39)$ & & $(0.00)$ & $(0.01)$ & & $(0.00)$ & $(0.02)$ \\
Submit Piece Rate & & & 0.30 & & & 0.29 & & 0.24 \\
& & & $(0.00)$ & & & $(0.07)$ & & $0.00)$ \\
\hline Observations & 84 & 84 & 84 & 84 & 84 & 84 & 168 & 168 & 168 \\
\hline \hline
\end{tabular}

The marginal effects are evaluated at an individual (a man in the last three columns), in the standard tournament, with a probability of winning of 0.33 and a change in the probability of winning of 0.16 , who submitted the piece rate performance to the tournament (columns 3,6, and 9) with a guess of winning (columns 2, 3, 5, 6, 8, and 9). We cluster on the participant to account for there being 2 observations for each of the 84 participants. $p$-values are in parenthesis.

\footnotetext{
${ }^{55}$ The coefficient on the female-affirmative action interaction does not capture the change in the gender gap between the standard and $\mathrm{AA}$ tournament. The change in the gender gap is given by $[\operatorname{Pr}(\mathrm{AA}=1, \mathrm{~F}=1, \mathrm{AA} \cdot \mathrm{F}=1 ; \mathrm{X})$ $\operatorname{Pr}(\mathrm{AA}=1, \mathrm{~F}=0, \mathrm{AA} \cdot \mathrm{F}=0 ; \mathrm{X})]-[\operatorname{Pr}(\mathrm{AA}=0, \mathrm{~F}=1, \mathrm{AA} \cdot \mathrm{F}=0 ; \mathrm{X})-\operatorname{Pr}(\mathrm{AA}=0, \mathrm{~F}=0, \mathrm{AA} \cdot \mathrm{F}=0 ; \mathrm{X})]$. Conditioning only on the probability of winning the change in the gap equals 0.76 . The additional controls for beliefs and the decision to submit the piece rate reduces the gap to 0.31 , thus 41 percent of the change in the gap is not accounted for.
} 


\section{VI: How Costly is AfFirmative Action}

The primary objective of affirmative action is to secure that a more diverse pool of applicants be selected as winners. The question of interest is how costly an improvement in diversity may be. To evaluate the cost of affirmative action we start by examining the consequences on earnings for the participants themselves. Since tournament entry is not payoff maximizing it is not obvious who will and will not benefit from the requirement that women be at least equally represented. We proceed by examining the effect affirmative action has on equity and on the performance of the selected participants. Specifically we ask how much lower the performance requirement will have to be for women, how many better performing men will have to be passed by to secure equal representation, and in particular the extent to which affirmative action will result in reverse discrimination. To answer these questions we will pay particular attention to the effect affirmative action has on the quality and gender composition of the pool of entrants.

\section{VI.A. Consequences for Participants}

Affirmative action affects individual payoffs through both institutional and behavioral changes, that is, payoffs are influenced both by changes in the probability of winning and the resulting changes in tournament entry. To decompose these two effects we compare the participant's expected earnings in the standard and AA tournament, as well as the earnings participants would have made had they been subjected to the change in the probability of winning but not changed their tournament-entry decisions. That is, we determine the expected earnings that would result had individuals stuck by their standard-tournament entry decisions (task 3) and been given the affirmative action probability of winning (task 4). The three expected payoff measures are reported by gender in Table VII. As anticipated, affirmative action increases the expected payoffs for women, while decreasing it for men. For women affirmative action increases earnings from 6.8 to 8.4. However had their entry decisions into the AA tournament been as those in the standard tournament, then the change in the probability of winning alone would result in expected payoffs of 7.5. Thus 45 percent of the increase in payoffs to women is accounted for by changes in the probability of winning, while the remainder results from changes in their tournament entry. By comparison the decrease in payoffs of men, from 13.4 to 10.0 , is primarily caused by changes in the probability of winning. Changes in the probability 
of winning alone decrease payoffs to 10.5 , thus accounting for 85 percent of the decrease. A similar pattern is seen for the subgroup of participants who have higher expected earnings from entering the AA tournament. Women in this group can attribute 75 percent of the increase in payoffs to behavioral changes, while 70 percent of the decrease in payoffs for men is due to changes in the probability of wining. Finally, men and women who in expectation are better off not entering the AA tournament are slightly worse off under affirmative action. For women this decrease in payoffs is driven by them making inferior tournament-entry decision under affirmative action, whereas the behavior of men improves their earnings.

TABLE X

EXPECTED PAYOFFS

\begin{tabular}{lllll}
\hline \hline Participants & Prob. of winning & Entry decision & Men & Women \\
\hline All & & & \\
& Standard & Standard & 13.4 & 6.8 \\
& AA & Standard & 10.5 & 7.5 \\
& AA & AA & 10.0 & 8.4 \\
\hline \multirow{2}{*}{ w/ positive exp. earnings from AA } & entry & & \\
& Standard & Standard & 27.1 & 10.8 \\
& AA & Standard & 21.4 & 12.2 \\
& AA & AA & 18.9 & 16.5 \\
\hline \multirow{5}{*}{ w/ negative exp. earnings from AA entry } & & \\
& Standard & Standard & 5.0 & 4.0 \\
& AA & Standard & 3.7 & 4.3 \\
& AA & AA & 4.5 & 2.9 \\
\hline \hline
\end{tabular}

\section{VI.B. Consequences for Performance and Equity}

While it is clear that affirmative action by mere design results in greater diversity among the winners, it is less clear how costly it will be for a firm to achieve this goal, nor is it clear how inequitable the resulting outcome may be. If we view those who enter competitions as applicants for jobs, and winners of the competition as those hired by the firm, then the costs of affirmative action depend critically on how many better performing men a firm will have to pass by to secure that women at least be equally represented. Passing by better performing candidates will not only be inequitable, but also impose a cost on firms who no longer are able to hire the best available candidates. To demonstrate these costs we examine the effect affirmative action has on the performance threshold applicants have to reach to get hired by the firm. Suppose a firm wants to hire say 20 applicants, then we ask what the minimum 
performance threshold will be for applicants to be selected when equal representation of women is or is not required. Crucial for determining these performance costs is the gender and performance of those who enter the competition. Given changes in tournament entry there is reason to believe that the anticipated performance costs calculated before the introduction of affirmative action may differ substantially from those actually experienced.

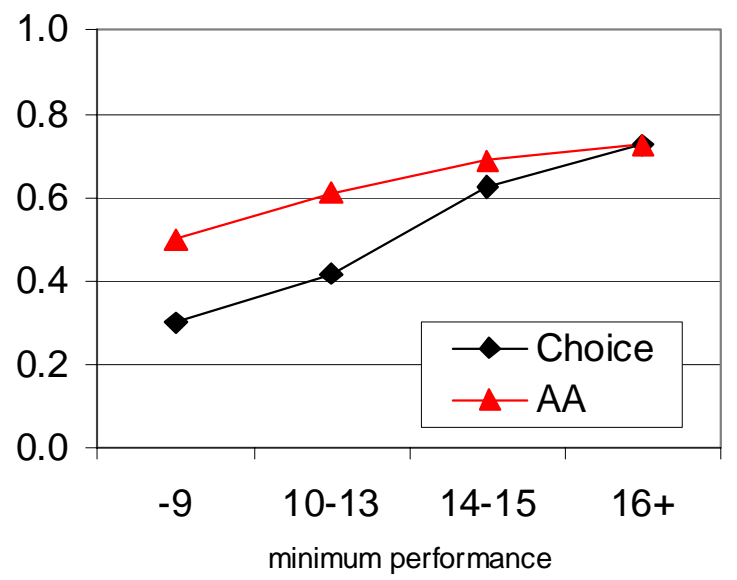

Panel A: Proportion of participants at a given performance who enter the tournament

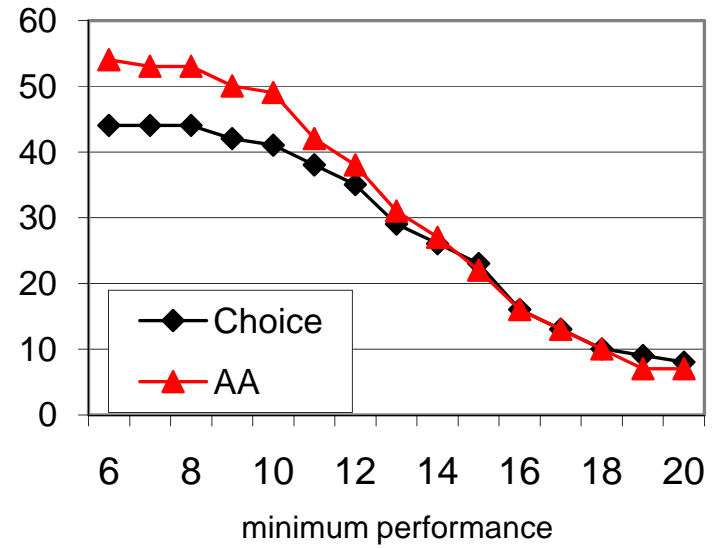

Panel B: Number of entrants with performance above a minimum threshold

Figure IV: Tournament Entry

To assess the performance costs associated with fulfilling the affirmative-action requirement, we focus on the actual performances after the compensation choice. Since the performance in task 4 is slightly higher than in task 3 , we rely on the task-3 performance. ${ }^{56} \mathrm{We}$ start by examining how changes in tournament entry under affirmative action affect the performance distributions of the pool of entrants. Figure IV Panel A shows the proportion of people with a given task-3 performance who choose to enter the standard or AA tournament. We see that affirmative action primarily increases entry for those who solve less than 14 problems, whereas there is little or no effect on entry for those with a performance of 14 problems or more. ${ }^{57}$ This finding is confirmed by Panel B, which shows the number of entrants who have performances at or above a certain level. While the pool of entrants with a minimum

\footnotetext{
${ }^{56}$ The results are similar when we use performances in task 2 or 4 , or if we use performance in task- 3 for entrants in the standard tournament and in task-4 for entrants in the AA tournament. Given the higher task-4 performance this later comparison would bias the results in favor of affirmative action.

${ }^{57}$ Less than ten percent of participants solve more than 20 problems, thus we focus the analysis on groups with minimum performances of 20 and below.
} 
performance below 14 is greater under affirmative action, there is no change in the number of entrants who have a minimum performance between 14 and 20 .

Affirmative action changes both the performance distribution and the gender composition of the pool of entrants. Figure V panel A shows the proportion of women among entrants whose performance is at or above a specified performance level. While the number of high-performing entrants is similar in the standard and AA tournament, the proportion of these entrants who are female is very different. For example, of the entrants in the standard tournament with a performance of 15 and higher only 26 percent are women, in contrast in the AA tournament 50 percent of these entrants are women. This difference in gender composition implies that when choosing participants with a performance of 15 and higher it will be costly to fulfill the affirmative action requirement among entrants in the standard tournament, but not when choosing among entrants in the AA tournament. Note that the same holds for entrants with a performance of 16 or lower, while there is never an equal representation of women in the standard tournament, at least 50 percent of these entrants are women in the AA tournament. That is, ex-post the affirmative action requirement will not imply that more qualified men will have to give way to less qualified women.

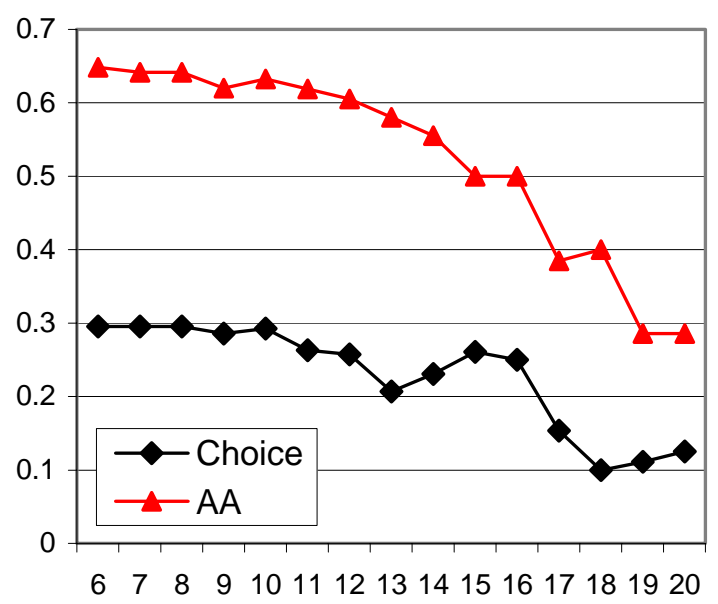

Panel A: Proportion of entrants above a minimum performance level who are women in Choice (task-3) and AA (task-4)

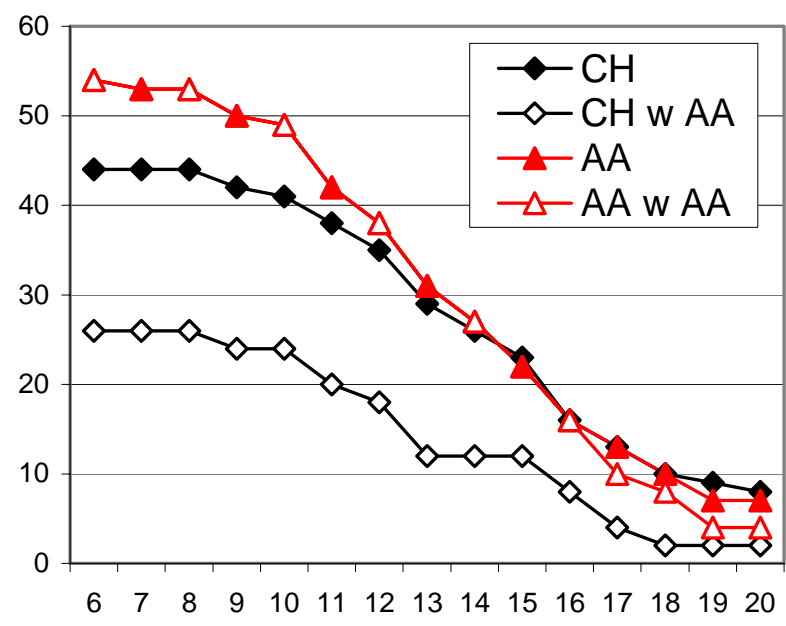

Panel B: Number of entrants above a minimum performance threshold in task-3 $(\mathrm{CH})$, in task-3 with AA requirement of equal representation of women ( $\mathrm{CH}$ w AA), and for task-4 without (AA) and with AA requirement (AA w AA).

Figure V: Performance of Entrants 
Figure V Panel B demonstrates the performance costs of affirmative action, when choosing among entrants in the standard tournament (task-3) and in the AA tournament (task-4). For each performance, say 15, panel B shows the number of entrants in the task-3 standard tournament $(\mathrm{CH})$ whose task-3 performance is 15 or higher, and similarly the number of entrants in the task-4 AA tournament (AA) with a task-3 performance at or above this level. Thus the $\mathrm{CH}$ and AA lines are identical to those of Panel B of Figure IV. In addition we also show the number of people who can be hired among the entrants satisfying a given minimum performance requirement, when there must be at least one woman for every man hired. For entrants in task 3 this is shown by the $\mathrm{CH}$ w AA line. Given the few high-performing women who enter the standard tournament, the enforcement of affirmative action implies that very few participants of a given minimum performance can be hired among entrants in the standard tournament. For example, for performances above 15, there are 23 entrants in the standard tournament and 22 in the AA tournament. However, when we require that for every man one woman has to be selected, then only 12 people can be hired among the standard entrants (in the standard tournament there are only six female entrants with a performance of 15 and higher). In contrast, all 22 entrants can be hired in the AA tournament (11 women have a performance of 15 and higher). Furthermore, to hire another pair of entrants in the standard tournament under the affirmative action rule, one has to lower the minimum performance requirement to 12 to add a woman, while passing by an additional 8 men with a higher performance. Using instead entrants in the AA tournament the same requirement implies that no men of higher performance are passed by to hire an additional woman. If we were to hire 22 entrants in the standard tournament and fulfill the affirmative action requirement, then we would have to lower the minimum acceptable performance threshold from 15 to 10 .

While affirmative action in the standard tournament implies that many more qualified men will be passed by to secure equal representation of women, such inequity does not arise once affirmative action is introduced and the minimum requirement for performance is 16 or less. This effect on reverse discrimination is further demonstrated in Figure VI, which shows for each minimum performance level the number of better performing men that must be passed by to secure that women be equally represented among those hired. The number of men affected by reverse discrimination is demonstrated by $\mathrm{CH}$ w AA when relying on entry in the standard tournament, and by AA w AA when relying on entry in the AA tournament. 


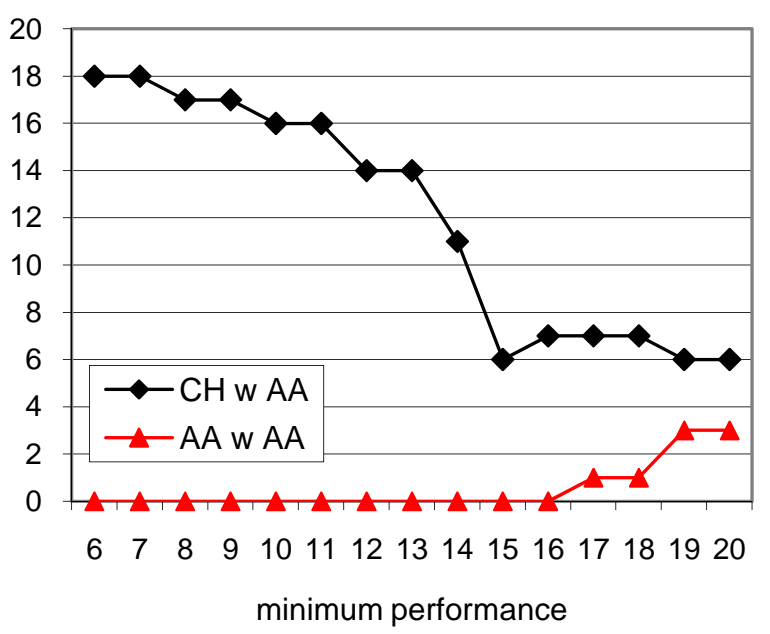

Figure VI: Number of better performing men passed by to secure equal representation of women given entry before AA ( $\mathrm{CH}$ w AA) vs. after AA (AA w AA)

Based on tournament entry prior to the introduction of affirmative action we anticipate substantial reverse discrimination. For example, returning to the case with a minimum performance requirement of 15 . We saw above that entry in the standard tournament would enable us to hire 12 people under the affirmative action requirement. As shown by the $\mathrm{CH} w$ AA line in Figure VI this implies that we would be passing by 6 men who have performances in excess of the required minimum for women. The introduction of affirmative action however cause women to be better represented among the set of applicants, and we would instead be able to hire an equally representative pool of 22 people with a minimum performance of 15 . As demonstrated by Figure VI, entry in the AA tournament implies that the requirement of equal representation does not cause better performing men to be passed by. Thus accounting for the changes in tournament entry the experienced degree of reverse discrimination is much smaller than anticipated.

The substantial difference between ex-post and ex-ante costs of affirmative action implies that it may be very expensive, in terms of performance loss and reverse discrimination, to apply the affirmative action rule 'secretly' or to introduce affirmative action after the participants have decided to enter a standard tournament. Furthermore, perceived inequity and performance costs may be vastly overestimated, if we fail to take into account that the pool of entrants will change along with a well-announced introduction of affirmative action. As many more women, and in particular many high-performing women, select to enter the AA tournament the gender composition of tournament entrants is very different under affirmative 
action. These changes in the entry pool imply that there are circumstances where it need not be costly to secure a more diverse set of winners, certainly it may be much cheaper than suggested by the pool of entrants into a standard tournament.

\section{CONCLUSION}

This paper contributes to the literature that tries to understand why women are underrepresented in many high-profile jobs and across whole professions. While discrimination and gender differences in preferences and ability help explain this gender gap, another explanation may be that men and women respond differently to competitive environments (see Gneezy and Rustichini, 2005, Gupta, Poulsen and Villeval, 2005, and Niederle and Vesterlund, 2007). Our study examines how and at what cost one can alter the institution used to select winners to entice more women to compete. Specifically, we investigate a quota-like affirmative action environment where we require that women be at least equally represented among those hired. Our analysis provides a deeper understanding of why women shy away from competition, and helps us understand which mechanisms we may use to change this behavior. Furthermore, we are able to examine the performance costs and reverse discrimination that may be associated with such an institutional change.

While affirmative action is expected to affect tournament entry through changes in the probability of winning, other factors could influence entry. Decisions may change because we mention affirmative action, and because the competition becomes more gender specific (e.g., a woman wins as long as she is the best performing woman). A more gender-specific competition can affect tournament entry by reducing gender differences in beliefs about relative performance, as well as gender differences in the willingness to compete.

We find that affirmative action causes a large increase in the tournament entry by women and a decrease in the entry by men. This change in behavior is not fully accounted for by changes in the probability in winning, rather the factors listed above all help explain why the gender gap in tournament entry differs under affirmative action.

Our experimental design allows us to characterize how the composition of the applicant pool changes with affirmative action. Replicating the finding that women shy away from competition, we find that prior to affirmative action only few high-performing women choose 
to compete. As a result, only rarely does a woman succeed in winning the tournament. ${ }^{58}$ Using this initial applicant pool the requirement that at least one woman must be hired for every man implies that very few participants can be hired when a specific minimum standard of performance has to be reached. This implies that to hire the same number of people the minimum performance standard has to be lowered substantially. Based on entry in the standard tournament the under representation of women causes affirmative action to be very costly as many more qualified men would have to be passed by to secure equal representation of women. The expected costs of affirmative action would still be substantial if the response to the institutional change only results from changes in the probability of winning. However, as mentioned above, we show that the introduction of affirmative action causes a response which is greater than that predicted by the probability of winning alone. While some high-performing men drop out of the competition, many women come in, and the overall number of highperforming participants in the entry pool is barely affected. This change in the gender composition of the applicant pool causes the ex post performance costs of affirmative action to be substantially smaller than those predicted ex ante.

Research on affirmative action has primarily focused on examining the consequences of changing the demand side of the market (see e.g. Coate and Loury, 1993, Fryer and Loury, 2005, and Holzer and Neumark, 2000, for an overview). That is, the focus has been on determining the consequences for diversity, performance, and reverse discrimination of altering the rules for admission and hiring. We show that in assessing the costs of affirmative action we need to also account for the indirect effects that occur through self selection into competitions. ${ }^{59}$ Specifically, we demonstrate that the effects of affirmative action on the set of applicants may be very large when entry decisions are not payoff maximizing. If we do not account for such changes in behavior we will exaggerate the costs of affirmative action.

\footnotetext{
${ }^{58}$ Note that this gender difference arises in the absence of any discrimination.

${ }^{59}$ While most affirmative action studies examine the direct effect on those admitted under the program, a few studies also account for the indirect effects on applicants. Long (2004) and Card and Krueger (2004) examine how the elimination of affirmative action in California and Texas influenced college applications. Long (2004) finds that fewer minority students send their SAT scores to top tier colleges, while Card and Krueger (2005) show that the policy does not influence the decisions of highly qualified minorities. Since the UC and UT systems rely on percentage rules whereby the top 4 vs. 10 percent of any graduating high school class are guaranteed admission, these analyses unfortunately do not enable us to determine if absent such programs we may observe 'sub-optimal' application decisions from highly qualified applicants.
} 


\section{References:}

Altonji, Joseph G., and Rebecca Blank "Race and Gender in the Labor Market." Handbook of Labor Economics, eds. O. Ashenfelter and D. Card, eds., Volume 3c Elsevier Science B.V., 1999, 3144-3259.

Ander, Richard, Gender and Jobs: Sex Segregation of Occupations in the World, International Labor Office: Geneva, 1998.

Andreoni, James, and Lise Vesterlund, "Which is the Fair Sex: Gender Differences in Altruism," Quarterly Journal of Economics, CXVI, 2001, 293 - 312.

Babcock, Linda and Sara Laschever, Women Don't Ask: Negotiation and the Gender Divide, Princeton University Press, September 2003.

Black, Sandra, and Philip E. Strahan, "The Division of Spoils: Rent-Sharing and Discrimination in a Regulated Industry," American Economic Review, XCI, 2001, 814831.

Blau, Francine D., and Lawrence M. Kahn, "The US Gender Pay Gap in the 1990s: Slowing Convergence," NBER working paper 10853, 2004.

Bertrand, Marianne and Kevin F. Hallock, "The Gender Gap in Top Corporate Jobs." Industrial and Labor Relations Review, LV, 2001, 3-21.

Beyer, Sylvia, "Gender Differences in the Accuracy of Self-Evaluations of Performance," Journal of Personality and Social Psychology, LIX, 1990, 960 - 970.

Beyer, Sylvia, and Edward M. Bowden, "Gender Differences in Self-Perceptions: Convergent Evidence From Three Measures of Accuracy and Bias," Personality and Social Psychology Bulletin, XXIII, 1997, 157 - 172.

Byrnes, James P., David C. Miller, and William D. Schafer, "Gender Differences in Risk Taking: A Meta-Analysis," Psychological Bulletin, LXXV, 1999, 367-383.

Campbell, Anne, A Mind of Her Own: The Evolutionary Psychology of Women (Oxford, UK: Oxford University Press, 2002).

Card, David and Alan B. Krueger, "Would the Elimination of Affirmative Action Affect Highly Qualified Minority Applicants? Evidence from California and Texas." Industrial and Labor Relations Review, 58(3), 2005, 416-434.

Coate, S. and Glenn C. Loury, "Will Affirmative-Action Policies Eliminate Negative Stereotypes?" American Economic Review, 83, 1993, 1220-1240.

Croson, Rachel and Uri Gneezy, "Gender differences in preferences," working paper, 2004.

Daly, Martin, and Margo Wilson, Sex, Evolution, and Behavior, 2nd ed. (Belmont, CA: Wadsworth Publishing Company, 1983)

DellaVigna, Stefano, Ulrike Malmendier, and Lise Vesterlund, "How Robust is Overconfidence? The Effect of Noisy and Non-Noisy Signals" in progress.

Dweck, Carol S., Self-Theories: Their Role in Motivation, Personality, and Development, 2000, Psychology Press, Philadelphia.

Eckel, Catherine C. and Philip J. Grossman, 2002a, "Sex and Risk: Experimental Evidence," forthcoming, Handbook of Experimental Economics Results, Amsterdam, Elsevier Science, North-Holland.

Eckel, Catherine, and Philip J. Grossman, 2002b, "Differences in the Economic Decisions of Men and Women: Experimental Evidence." Forthcoming in Handbook of Experimental Results, edited by C. Plott and V. Smith. New York, Elsevier.

Fischbacher, Urs (2007), "z-Tree: Zurich Toolbox for Ready-made Economic experiments," Experimental Economics, 10(2), 171-178. 
Fryer, Roland G. Jr, and Glenn C. Loury, "Affirmative Action and Its Mythology", The Journal of Economic Perspectives, Summer 2005.

Gneezy, Uri, Kenneth Leonard, and John List, "Gender Differences in Competition: The Role of Socialization," 2006, working paper.

Gneezy, Uri, Muriel Niederle, and Aldo Rustichini, "Performance in Competitive Environments: Gender Differences," Quarterly Journal of Economics, August 2003, p. 1049-1074.

Gneezy, Uri and Aldo Rustichini, "Executive versus Teachers: Gender, Competition and SelfSelection", November 2005, working paper.

Goldin, Claudia, and Cecilia Rouse, "Orchestrating Impartiality: The Impact of "Blind" Auditions on Female Musicians," American Economic Review, XL, 2000, 715-742.

Grusky, David B. and England, Paula, Occupational Ghettos, 2004, Stanford University Press: California.

Gupta, Nabanita Datta, Anders Poulsen and Marie-Claire Villeval, "Male and Female Competitive Behavior - Experimental Evidence", November 2005, GATE working paper, Ecully, France.

Harwarth, Irene, Mindi Maline, and Elizabeth DeBra, "Women's Colleges in the United States: History, Issues, and Challenges," Office of Educational Research and Improvement at the U. S. Department of Education report, 1997.

Hewlett, Sylvia Ann and Carolyn Buck Luce "Off Ramps and On-Ramps, Keeping Talented Women on the Road to Success," Harvard Business Review, March 2005.

Holzer, Harry, and David Neumark, "Assessing Affirmative Action," Journal of Economic Literature, 2000, 483-568.

Lichtenstein, Sarah, Baruch Fischhoff, and Lawrence Phillips, "Calibration and Probabilities: The State of the Art to 1980", in Judgment Under Uncertainty: Heuristics and Biases, Daniel Kahneman, Paul Slovic and Amos Tversky, eds., (Cambridge University Press: 1982).

Long, Mark C., "College Applications and the Effect of Affirmative Action." Journal of Econometrics, 121 (1-2), July-August 2004, 319-342.

Niederle, Muriel and Lise Vesterlund, "Do Women Shy Away From Competition? Do Men Compete Too Much?" Quarterly Journal of Economics, 2007, 122, 3, 1067-1101.

Niederle, Muriel, Carmit Segal, and Lise Vesterlund, "Can Changing the Prizes Affect Gender Gaps in Competitive Task Selection? An Experimental Approach" in progress.

Page, Scott E., The Difference: How the Power of Diversity Creates Better Groups, Firms, Schools, and Societies, Princeton University Press, 2007.

Roberts, Tomi-Ann and Susan Nolen-Hoeksama, "Sex Differences in Reactions to Evaluative Feedback", Sex Roles, 1989, Vol.21, Nos11/12, 725-747.

Ruble, Diane N., Carol L. Martin, and Sheri A. Berenbaum, "Gender Development," in Handbook of Child Psychology, 6th ed., William Damon and Richard M. Lerner, eds. (New York: Wiley, 2006), Vol. 3, Chapter 14, pp. 858-932.

Solnick, Sara J., "Changes in Women's Majors from Entrance to Graduation at Women's and Coeducational Colleges," Industrial and Labor Relations Review, 1995, XLVIII, 505514.

Steele, Claude M., "A Threat in the Air: How Stereotypes Shape Intellectual Identity and Performance," American Psychologist, LII, 1997, 613 - 629. 
Weeden, Kim A. "Profiles of Change: Sex Segregation in the United States, 1910-2000." in Occupational Ghettos, by Maria Charles and David Grusky. Stanford: Stanford University Press, 2004, 131-78. 


\section{INSTRUCTIONS}

\section{WELCOME}

In the experiment today you will be asked to complete six different tasks. None of these will take more than 5 minutes. At the end of the experiment you will receive $\$ 5$ for having completed the experiment. In addition, we will randomly select one of the tasks and pay you based on your performance in that task. Once you have completed the six tasks we determine which task counts for payment by drawing a number between 1 and 6 . The method we use to determine your earnings varies across tasks. Before each task we will describe in detail how your payment is determined.

Your total earnings from the experiment are the sum of your payment for the randomly selected task, your $\$ 5$ payment for completing the experiment, and a $\$ 10$ show up fee. At the end of the experiment you will be asked to come to the side room where you will be paid in private.

\section{Task 1 - Piece Rate}

For Task 1 you will be asked to calculate the sum of five randomly chosen two-digit numbers. You will be given 5 minutes to calculate the correct sum of a series of these problems. You cannot use a calculator to determine this sum, however you are welcome to write the numbers down and make use of the provided scratch paper. You submit an answer by clicking the submit button with your mouse. When you enter an answer the computer will immediately tell you whether your answer is correct or not. Your answers to the problems are anonymous.

If Task 1 is the one randomly selected for payment, then you get 50 cents per problem you solve correctly in the 5 minutes. Your payment does not decrease if you provide an incorrect answer to a problem. We refer to this payment as the piece rate payment.

Please do not talk with one another for the duration of the experiment. If you have any questions, please raise your hand.

\section{ARE THERE ANY QUESTIONS BEFORE WE BEGIN?}

\section{Task 2 - Tournament}

As in Task 1 you will be given 5 minutes to calculate the correct sum of a series of five 2 digit numbers. However for this task your payment depends on your performance relative to that of a group of other participants. Each group consists of six people, 3 men and 3 women. The five other members of your group are located in the same row as you, that is, you are paired with the people sitting in front of you and those sitting behind you.

If Task 2 is the one randomly selected for payment, then your earnings depend on the number of problems you solve compared to the five other people in your group. The two individuals who correctly solve the largest number of problems will receive $\$ 1.5$ per correct problem, while the other participants receive no payment. We refer to this as the tournament payment. If 
there are ties the winner will be randomly determined. You will not be informed of how you did in the tournament until all six tasks have been completed.

Please do not talk with one another. If you have any questions, please raise your hand.

\title{
ARE THERE ANY QUESTIONS BEFORE WE BEGIN?
}

\author{
Task 3 - Choice
}

As in the previous two tasks you will be given 5 minutes to calculate the correct sum of a series of five 2-digit numbers. However, you now have to choose which payment scheme you want for your performance on the third task. You can either choose to be paid according to the piece rate, or according to the tournament.

If Task 3 is the one randomly selected for payment, then your earnings for this task are determined as follows. If you choose piece rate you receive 50 cents per problem you solve correctly. If you choose tournament your performance will be evaluated relative to the performance of the other five participants of your group in the Task 2-tournament. Task 2tournament is the task you just completed. If you correctly solve more problems than 4 participants did in the task 2-tournament, then you receive three times the payment from the piece rate, that is, $\$ 1.5$ per correct problem. That is, at most only one participant in your group can have a higher task 2-tournament performance than your task-3 performance. Otherwise, you receive no earnings for this task. If there are ties, then the ranking is determined randomly. Remember, your group consists of all individuals that sit in the same row as yourself. Every group has 3 men and 3 women. You will not be informed of how you did in the tournament until all six tasks have been completed.

The next computer screen will ask you to choose whether you want the piece rate or the tournament applied to your performance. You will then be given 5 minutes to calculate the correct sum of a series of five randomly chosen two-digit numbers.

Please do not talk with one another. If you have any questions, please raise your hand.

\section{ARE THERE ANY QUESTIONS BEFORE WE BEGIN?}

\section{Affirmative-Action Tournament}

Before we start the next task we explain the rules of an affirmative-action tournament. In an affirmative-action tournament the winners are determined as follows. One winner will be the best performing woman in a group. The other winner is the best performing individual among the rest of the group members (i.e., excluding the best performing woman).

Let us look at a concrete example that illustrates how the winners in an affirmative-action tournament are determined. We order the group members within each gender according to their 
performance such that w1 is the best performing woman, w2 is the second best performing woman, etc. We order the men in a similar manner, i.e., $\mathrm{m} 1$ is the best performing man, $\mathrm{m} 2$ is the second best performing man, etc. The best performing woman, wl, is always one of the two winners in the affirmative-action tournament. To determine the second winner we need to find out who is the best performing individual among the remaining members of the group (i.e., all group members excluding w1). Since there is going to be only one other winner it can only be $\mathrm{w} 2$ or $\mathrm{m} 1$. Thus, if the performance of $\mathrm{w} 2$ is higher than the performance of $\mathrm{m} 1$, then she is the second winner. If $\mathrm{w} 2$ performed worse than $\mathrm{m} 1$, then $\mathrm{m} 1$ is the second winner.

To summarize a woman will win an affirmative-action tournament if she is the best performing woman or if she is among the two best performing individuals in the group. A man wins an affirmative-action tournament if he is the best performing man and if he is among the two best performing individuals in the group. Thus there is at least one woman and at most one man among the winners in an affirmative-action tournament.

\section{NEXT PAGE}

\section{Task 4 - Choice II}

As in the previous three tasks you will be given 5 minutes to calculate the correct sum of a series of five 2-digit numbers. Again, you now have to choose which payment scheme you want for your performance on the fourth task. You can either choose to be paid according to the piece rate, or according to the affirmative-action tournament.

If Task 4 is the one randomly selected for payment, then your earnings for this task are determined as follows. If you choose the piece rate you receive 50 cents per problem you solve correctly. If you choose the affirmative-action tournament your performance will be evaluated relative to the performance of other participants in your group in the Task 2-tournament. Task 2 -tournament is the second task you completed. The instructions for women are that you receive $\$ 1.5$ per correct problem if (1) you correctly solve more problems than 4 participants did in the task 2-tournament, or (2) you correctly solve more problems than the other 2 women did in the task 2-tournament. Otherwise, you receive no earnings for this task. The instructions for men are that you receive $\$ 1.5$ per correct problem if (1) you correctly solve more problems than 4 participants did in the task 2-tournament, and (2) you correctly solve more problems than the other 2 men did in the task 2-tournament. Otherwise, you receive no earnings for this task. For both, women and men, if there are ties, then the ranking is determined randomly. Remember, your group consists of all individuals that sit in the same row as yourself. Every group has 3 men and 3 women. You will not be informed of how you did in the tournament until all six tasks have been completed.

The next computer screen will ask you to choose whether you want the piece rate or the affirmative-action tournament applied to your performance. You will then be given 5 minutes to calculate the correct sum of a series of five randomly chosen two-digit numbers.

Please do not talk with one another. If you have any questions, please raise your hand. 


\title{
ARE THERE ANY QUESTIONS BEFORE WE BEGIN?
}

\author{
Task 5 - Submit Piece Rate
}

You do not have to add any numbers for the fifth task of the experiment. Instead you may be paid one more time for the number of problems you solved in the Task 1 . However, you now have to choose which payment scheme you want applied to the number of problems you solved in Task 1-Piece Rate. You can either choose to be paid according to the piece rate, or according to the tournament.

If the fifth task is the one selected for payment, then your earnings for this task are determined as follows. If you choose the piece rate you receive 50 cents per problem you solved in Task 1 . If you choose the tournament your performance will be evaluated relative to the performance of the other five participants of your group in the Task 1-piece rate. If you correctly solved more problems than 4 participants did in the task 1-piece rate, then you receive three times the payment from the piece rate, that is, $\$ 1.5$ per correct problem. That is, at most only one participant in your group can have a higher task 1 performance than you. Otherwise, you receive no earnings for this task. If there are ties, then the ranking is determined randomly.

Remember, your group consists of all individuals that sit in the same row as yourself. Every group has 3 men and 3 women. You will not be informed of how you did in the tournament until all six tasks have been completed.

The next computer screen will tell you how many problems you correctly solved in Task 1, and will ask you to choose whether you want the piece rate or the tournament applied to your performance.

Please do not talk with one another. If you have any questions, please raise your hand.

\section{ARE THERE ANY QUESTIONS BEFORE WE BEGIN?}

\section{Task 6 - Submit Piece Rate II}

You do not have to add any numbers for the sixth and final task of the experiment. Instead you may be paid one more time for the number of problems you solved in the Task 1 . However, you now have to choose which payment scheme you want applied to the number of problems you solved in Task 1. You can either choose to be paid according to the piece rate, or according to the affirmative-action tournament.

If the sixth task is the one selected for payment, then your earnings for this task are determined as follows. If you choose the piece rate you receive 50 cents per problem you solved in Task 1 . If you choose the affirmative-action tournament your performance will be evaluated relative to the performance of other participants in your group in Task 1-piece rate. The instructions for women are that you receive $\$ 1.5$ per correct problem if (1) you correctly solved more problems 
than 4 participants did in the task 1-piece rate, or (2) you correctly solved more problems than the other 2 women did in the task 1-piece rate. Otherwise, you receive no earnings for this task. The instructions for men are that you receive $\$ 1.5$ per correct problem if (1) you correctly solved more problems than 4 participants did in the task 1-piece rate, and (2) you correctly solved more problems than the other 2 men did in the task 1-piece rate. Otherwise, you receive no earnings for this task. For both, women and men, if there are ties, then the ranking is determined randomly.

Remember, your group consists of all individuals that sit in the same row as yourself. Every group has 3 men and 3 women. You will not be informed of how you did in the tournament until all six tasks have been completed.

The next computer screen will tell you how many problems you correctly solved in Task 1, and will ask you to choose whether you want the piece rate or the tournament applied to your performance.

Please do not talk with one another. If you have any questions, please raise your hand.

ARE THERE ANY QUESTIONS BEFORE WE BEGIN? 